\title{
Inventário florestal a $100 \%$ em pequenas áreas sob manejo florestal madeireiro
}

\begin{abstract}
Henrique José Borges de ARAUJO ${ }^{1}$
RESUMO

O inventário é uma etapa básica do manejo florestal em que é avaliado a composição da floresta e a sua potencialidade para o manejo. O inventário a $100 \%$ tem o propósito de determinar o estoque de madeira existente para fins de planejamento da exploração. Este trabalho apresenta resultados de inventário florestal a $100 \%$ de um projeto de manejo florestal comunitário madeireiro conduzido pela Embrapa Acre em parceria com um grupo de produtores do Projeto de Colonização Pedro Peixoto, no estado Acre. A área total inventariada foi de 206,8 ha, composta por 57 talhões de tamanho médio de 3,6 ha cada um, correspondente a $48 \%$ da área total sob manejo de 12 pequenas propriedades. Foram abordadas todas as árvores com $\mathrm{DAP}^{3}$ a $50,0 \mathrm{~cm}$. Os resultados foram expressos, por espécie, por propriedade e para a área total em: número total de árvores $(\mathrm{NT})$; abundância por hectare $(\mathrm{AB})$; volume total $(\mathrm{VT})$; volume por hectare $(\mathrm{V})$; área basal total (ABsT); área basal por hectare (ABs); índice de importância da espécie (IND); e condição de aproveitamento da tora. Para a área total os resultados foram: $\mathrm{NT}=3.518$ árvores; $\mathrm{AB}=17,01$ árvores.ha ${ }^{-1} ; \mathrm{VT}=21.667,41 \mathrm{~m}^{3} ; \mathrm{V}$ $=104,77 \mathrm{~m}^{3} \cdot \mathrm{ha}^{-1} ; \mathrm{ABsT}=1.413,77 \mathrm{~m}^{2} ; \mathrm{e} \mathrm{ABs}=6,84 \mathrm{~m}^{2} \cdot \mathrm{ha}^{-1}$. Foram reconhecidas em campo 204 espécies, pertencentes a 136 gêneros e a 43 famílias. Foi observado acentuada concentração dos dados dendrométricos em poucas espécies, pois somente cinco espécies respondem por um terço $(33,6 \%)$ do IND total.
\end{abstract}

PALAVRAS-CHAVE

Inventário florestal, manejo florestal comunitário, espécies florestais, Projeto de Colonização Pedro Peixoto.

\section{Forest inventory to $100 \%$ in small areas under wood forest management}

\begin{abstract}
The inventory is a basic stage of the forest management in that is evaluated the composition of the forest and its potentiality for the management. The inventory to 100\% has the purpose of determining the stock existent of wood logs for ends of planning of the exploration. This paper presents results of forest inventory to $100 \%$ of a wood forest management communitary project lead by Embrapa Acre in partnership with a group of small farmers of the Pedro Peixoto Colonization Project, in the State of Acre, Brazilian Amazonian region. The inventoried total area was of $206,8 \mathrm{ha}$, composed by 57 compartments with average size of 3,6 ha each one, corresponding to $48 \%$ of the total area under management of 12 small properties. Were included all the trees with $D B H^{3}$ to $50,0 \mathrm{~cm}$. The results were expressed, for species, for property and for the total area in: total amount of trees (NT); amount of trees for hectare (AB); total volume (VT); volume for hectare (V); total basal area (ABsT); basal area for hectare (ABs); index of importance of the species (IND); and condition of use of the log. The results for the total area were: $N T=3.518$ trees; $A B=17,01$ trees. $h a^{-1} ; V T=21.667,41 \mathrm{~m}^{3} ; V=104,77 \mathrm{~m}^{3} \cdot h a^{-1} ; A B s T=1.413,77 \mathrm{~m}^{2} ; e A B s=$ $6,84 \mathrm{~m}^{2} . \mathrm{ha}^{-1}$. In the inventoried area 204 species were recognized, belonging to 136 botanical genera and 43 familiae. Was observed accentuated concentration of the dendrometric data in few species, because only five species answer for a third (33,6\%) of the total IND.
\end{abstract}

\section{KEY WORDS}

forest inventory, communitary forest management, forestspecies, Pedro Peixoto Colonization Project. 


\section{INTRODUÇÃO}

Entre as etapas fundamentais do ordenamento de atividades de manejo florestal esta a avaliação acerca da composição da floresta a ser manejada. Essa avaliação é feita por meio de inventários florestais, os quais qualificam e quantificam os recursos referentes às espécies vegetais ocorrentes, especialmente as árvores lenhosas, quanto aos seus dados dendrométricos (número de indivíduos, diâmetros, áreas basais, volumes do fuste, etc.).

Os inventários florestais fornecem os subsídios necessários para o planejamento das atividades de exploração e do manejo propriamente dito, tais como: espécies a explorar, intensidades e ciclos de corte, tratamentos silviculturais a serem conduzidos, necessidade de plantios de enriquecimento, etc. Outro aspecto importante da avaliação dos recursos existentes na floresta é a possibilidade de projeções de ordem econômicas e referentes à comercialização, tais como: cálculos de despesas e receitas esperadas, mercados a atingir, etc.

Basicamente, os inventários em florestas destinadas ao uso sustentado podem ser de três tipos: a) Inventário de reconhecimento, ou diagnóstico: é realizado em áreas onde se pretende implantar um plano de manejo. Seu propósito é analisar a composição e a estrutura da floresta, abordando indivíduos desde a regeneração natural até árvores adultas e permitindo determinar seu potencial e aptidão para o manejo. Este tipo de inventário é feito por métodos de amostragem em bases estatísticas em que são mensuradas e avaliadas, a uma intensidade amostral pré-estabelecida, parcelas de áreas de floresta, cujos resultados são estendidos à área total a ser manejada; b) Inventário a 100\%, ou pré-exploratório: é realizado em áreas onde está em execução um plano de manejo florestal. Tem o propósito de determinar, com bom grau de precisão, o estoque de madeira existente nos compartimentos de manejo para fins de planejamento da exploração. Este inventário é denominado de $100 \%$ em razão de que é realizado em toda a área de interesse e onde são abordadas todas as árvores adultas ocorrentes a partir de um DAP mínimo estabelecido (p.ex.: 50,0 cm), mapeando-as e classificando-as quanto ao estado de aproveitamento, destinação de uso (p.ex.: exploração, estoque ou porta-sementes), etc. Em geral, é feito logo antes da exploração florestal, de modo a possibilitar a definição das espécies a explorar e os respectivos volumes; e c) Inventário contínuo, ou de monitoramento: pode ser realizado em áreas de floresta em qualquer situação (sob manejo ou não). Visa analisar e acompanhar o desenvolvimento estrutural de uma floresta ao longo do tempo por meio de mensuraçôes sucessivas, abordando indivíduos desde a regeneração natural até árvores adultas. Sua finalidade é avaliar o comportamento de uma floresta frente às causas naturais de alteração e, principalmente, às intervenções de exploração promovidas por atividades de manejo florestal. Neste tipo de inventário são avaliados ingressos e mortalidade de árvores, crescimento volumétrico, reações da regeneração natural, danos provocados pela exploração, etc.
Este trabalho apresenta resultados de inventário florestal a $100 \%$ realizado em talhões de exploração florestal de pequenas propriedades componentes de um projeto de manejo florestal madeireiro comunitário conduzido pela Embrapa Acre em parceria com um grupo de produtores rurais do Projeto de Colonização Pedro Peixoto, no estado do Acre.

\section{MATERIAL E MÉTODOS}

\section{LOCALIZAÇÃO E CARACTERÍSTICAS DA ÁREA INVENTARIADA}

A área inventariada é composta por 57 talhões de exploração florestal de 12 pequenas propriedades localizadas no Projeto de Colonização Pedro Peixoto, extremidade leste do estado do Acre, Ramais Nabor Junior e Granada, às margens da rodovia BR364, trecho Rio Branco-Porto Velho, distando, em média, a 110 km da capital Rio Branco (Figura 1).

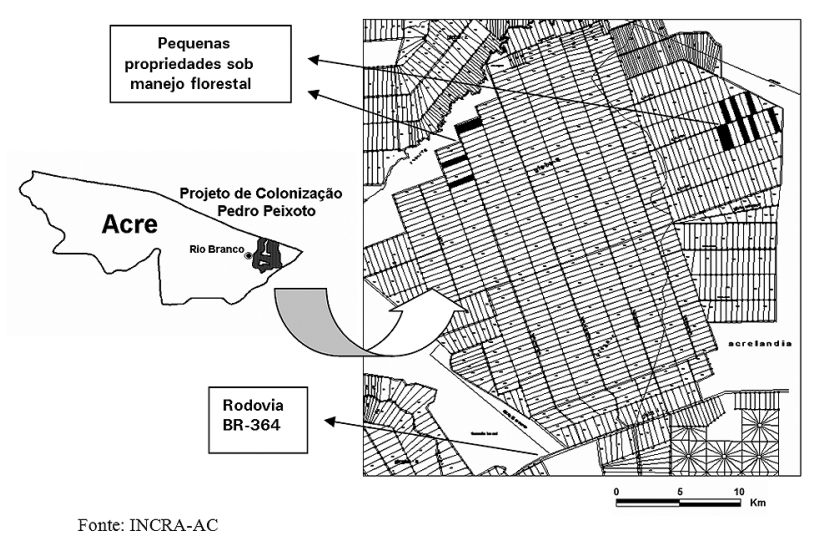

Figura 1 - Mapa parcial do Projeto de Colonização Pedro Peixoto onde estão localizadas as pequenas propriedades sob manejo florestal.

O PC Pedro Peixoto possui área total de 378.395 ha e abriga cerca de 3.000 famílias (Cavalcanti, 1994). Os solos, em geral, são de baixa fertilidade, ocorrendo, porém, pequenas manchas com bom potencial agrícola. O clima é tipicamente tropical, bastante quente e úmido, composto de estaçôes de seca (maio a outubro) e de chuva (novembro a abril) bem definidas. A temperatura média anual situa-se em torno de $25^{\circ} \mathrm{C}$. As precipitações anuais variam de 1.700 a $2.400 \mathrm{~mm}$. A umidade relativa do ar é elevada, situando-se, em média, acima dos $80 \%$. A cobertura florestal é constituída por típica floresta tropical primária densa de terra firme amazônica. Atualmente, estima-se em 50 a $60 \%$ a alteração da cobertura florestal original, principalmente na formação de pastagens e desmatamentos para agricultura em pequena escala (subsistência).

Em média, as pequenas propriedades componentes do projeto de manejo florestal possuem área total de $72 \mathrm{ha}$, com cobertura florestal primária variando entre 60 a $80 \%$ dessa área, sendo o restante, áreas alteradas para fins agrícolas ou de pecuária. 
A área efetivamente sob manejo florestal de cada propriedade, corresponde à metade $(50 \%)$ da sua área total, equivalendo, portanto, em média, a 36 ha e é localizada, em relação à estrada de acesso, na sua parte posterior. Aárea total sob manejo das 12 propriedades é de 431 ha.

A área sob manejo das propriedades é parte da sua Reserva Legal, cujo uso econômico, segundo a lei (Lei no 4771, de 15.09.65, atualmente regulamentada por MP's, que estabelecem em $80 \%$ a cobertura florestal a ser mantida), só é possível através do próprio manejo ou extrativismo tradicional. O sistema de manejo proposto para as propriedades do PC Peixoto possibilita dotar a parte que é preservada por lei, vista pelos produtores como um empecilho à expansão agropecuária, em uma atrativa alternativa econômica, reduzindo as chances de sua remoção.

\section{SÍNTESE DO PLANO DE MANEJO FLORESTAL}

Em linhas gerais, segundo Araujo (1998), o plano de manejo florestal das áreas do PC Peixoto consiste em dividir a parte sob manejo das propriedades em 10 compartimentos (talhões) de igual tamanho (aproximadamente 3,6 ha cada), explorando-se um ao ano, a uma intensidade exploratória média em torno de $8,0 \mathrm{~m}^{3} \cdot \mathrm{ha}^{-1}$. O ciclo de corte é, portanto, de dez anos. A Figura 2 mostra uma representação esquemática padrão de uma pequena propriedade sob manejo florestal.

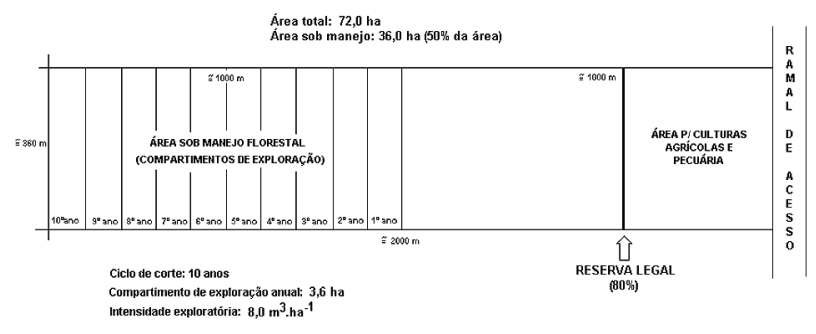

Figura 2 - Desenho esquemático de uma pequena propriedade sob manejo florestal do Projeto de Colonização Pedro Peixoto.

A intensidade exploratória de $8,0 \mathrm{~m}^{3} \cdot \mathrm{ha}^{-1}$ representa cerca de um quinto das recomendaçôes para o manejo florestal na Amazônia brasileira. Resultados de pesquisas em manejo florestal na Amazônia indicam uma intensidade exploratória e um ciclo de corte ótimos de $40 \mathrm{~m}^{3} \cdot$ ha $^{-1}$ e 30 anos, respectivamente (Silva, 1990; Higuchi \& Vieira, 1990). Essas recomendaçōes são baseadas na produtividade volumétrica média de uma floresta manejada, que é situada em aproximadamente $2,0 \mathrm{~m}^{3} \cdot \mathrm{ha}^{-1}$. ano. Assim, em termos de recomposição ou rotação sustentável da floresta, a expectativa é de que o curto ciclo de corte de dez anos previsto para as propriedades do PC Peixoto, seja compensado pela baixa intensidade exploratória de $8,0 \mathrm{~m}^{3} \cdot \mathrm{ha}^{-1}$.

Estudos básicos realizados mostraram que as áreas possuem potencial de médio a bom para o manejo florestal. De acordo com Araujo \& Oliveira (1996), o inventário de reconhecimento, ou diagnóstico, revelou a ocorrência (árvores com DAP 3 10,0 $\mathrm{cm}$ ) de aproximadamente 300 espécies que apresentaram uma distribuição diamétrica bastante equilibrada, abundância de 375 árvores.ha ${ }^{-1}$, área basal de 21,96 $\mathrm{m}^{2} \cdot \mathrm{ha}^{-1}$, volume de 180,36 $\mathrm{m}^{3} \cdot \mathrm{ha}^{-1}$ e volume comercial (árvores com DAP $350,0 \mathrm{~cm}$ ) de $73,07 \mathrm{~m}^{3} \cdot \mathrm{ha}^{-1}$.

Os trabalhos de exploração florestal são, normalmente, iniciados nos meses de maio ou junho, estendendo-se até setembro a outubro. Nesse período, as atividades de manejo florestal são perfeitamente compatibilizadas com as outras atividades do calendário agrícola dos produtores (agricultura, pecuária e extrativismo), além das condiçōes climáticas serem mais favoráveis, pois é o período de estiagem amazônico.

As operaçôes de exploração são caracterizadas pela simplicidade operacional, dispensando investimentos elevados e de fácil assimilação e domínio por parte do produtores manejadores. Outro aspecto importante é de que são pouco agressivas à floresta, pois os danos são muito menores quando comparados com uma exploração convencional mecanizada.

A exploração é realizada sem utilização de máquinas pesadas. As árvores são derrubadas de maneira a reduzir ao máximo o dano na floresta através de derrubada orientada (queda direcionada para o lado que houver menor ocorrência de arvores em desenvolvimento). O processamento primário das toras (desdobro em peças de madeira serrada, tais como tábuas, vigas, etc.) é executado ainda dentro da floresta utilizando serraria portátil ou motosserra. $\mathrm{O}$ transporte da madeira processada, na forma de peças serradas, da mata até as vias de escoamento, é realizado por animais, após, é carregada em caminhões e transportada até os centros de processamento e consumo.

\section{INVENTÁRIO FLORESTAL A 100\%}

No caso do sistema de manejo do PC Peixoto, no inventário florestal a 100\% são abordadas todas as árvores ocorrentes com DAP ${ }^{3}$ a 50,0 cm, sendo que, para cada árvore, são tomadas informações sobre a denominação usual da espécie, mensurado o DAP, observada as condiçôes de aproveitamento da tora e feita a plotação em croqui.

Em campo, a realização do inventário a $100 \%$ inclui as seguintes etapas: a) abertura das picadas laterais fronteiriças das propriedades (relativas à parte de floresta sob manejo) e das picadas delimitadoras (centro e bordas) dos talhões de exploração. As picadas são abertas com terçado (facão), sendo que a direção de abertura (rumo e retidão) é aferida por meio de bússola e de balizas (varetas obtidas na mata), e as distâncias medidas por trenas; b) caminhamento longitudinal em "ziguezague" em cada uma das duas metades do talhão (cada metade possui $50 \mathrm{~m}$ de largura e, em média, $360 \mathrm{~m}$ de comprimento) para abordagem das árvores. Quando abordadas, além da tomada das informaçōes dendrometricas e mapeamento (plotação em croqui), as árvores também recebem plaquetas de identificação contendo o número 
seqüencial (dentro do talhão) e respectivo número do talhão.

A identificação em campo das espécies (denominação usual) foi realizada por mateiros experientes, utilizando-se de observaçōes das folhas, casca, lenho, exsudaçôes, etc. Vale citar que atualmente já existem mateiros habilitados entre o grupo de produtores do projeto.

Com auxílio de uma fita métrica, são tomadas as CAP's (circunferências à altura do peito), que posteriormente são convertidas em DAP's.

A condição de aproveitamento da tora pode ser: 1) tora com aproveitamento total; 2) tora com aproveitamento parcial; e 3) tora sem aproveitamento. Esta classificação é definida em função dos defeitos existentes (tortuosidade, presença de podridão, oco ou rachaduras, etc.) e fornece um indicativo do estado da árvore, com vistas ao aproveitamento possível para peças de madeira serradas.

A plotação das árvores em croqui é realizada de modo aproximado, tendo como referenciais as picadas feitas no centro e nas bordas dos compartimentos.

São apresentados nos Anexos 1 e 2, respectivamente, um modelo da ficha de campo utilizada no inventário florestal a $100 \%$ e um exemplo de croqui com as árvores plotadas.

Embora não seja quantificado o nível de aproveitamento em termos volumétricos, ou percentuais, a condição de aproveitamento da tora é um critério de escolha para o abate da árvore (as árvores com defeitos são mantidas), juntamente com a abundância (árvores.ha $\left.{ }^{-1}\right)$, volume $\left(\mathrm{m}^{3} \cdot \mathrm{ha}^{-1}\right)$ e a manutenção de árvores porta-sementes.

Os resultados do inventário pré-exploratório são expressos, por espécie, em: a) número total de árvores (NT) na área inventariada; b) abundância (número de árvores) por hectare $(\mathrm{AB})$; c) volume total das árvores em pé (VT) na área inventariada; d) volume por hectare das árvores em pé (V); e) área basal total $(\mathrm{ABs} T)$ na área inventariada; $\mathrm{f}$ ) área basal por hectare (ABs); g) índice de importância da espécie em percentual (IND); e, h) condição de aproveitamento da tora em percentual (total, parcial e sem aproveitamento).

$\mathrm{O}$ volume individual da árvore em pé $(\mathrm{V})$ corresponde ao volume potencialmente aproveitável da tora com casca, tendo como componentes de cálculo o DAP e a altura comercial, a qual, normalmente, é iniciada na base da árvore, junto ao solo, estendendo-se até as primeiras galhadas ou bifurcaçôes. Esse volume é estimado pela equação (1) matemática de simples entrada (Araujo, 1998):

$\mathrm{V}=-0,692349+0,001339 \mathrm{DAP} 2$

Onde:

$\mathrm{V}=$ volume individual da árvore em pé, $\mathrm{em}^{3}$

$\mathrm{DAP}=$ diâmetro à altura do peito $(1,30 \mathrm{~m}), \mathrm{em} \mathrm{cm}$
O índice de importância da espécie (IND) é um valor percentual, expresso pela média aritmética simples dos percentuais de cada espécie para NT, VT e ABsT, em relação aos respectivos totais (todas as espécies) dessas variáveis para a área inventariada (Araujo, 2002). É dado pela expressão:

$\mathrm{IND}_{\mathrm{i}}=\frac{\left(\frac{\mathrm{NT}_{\mathrm{i}}}{\mathrm{NT}_{\text {total }}} 100\right)+\left(\frac{\mathrm{VT}_{\mathrm{i}}}{\mathrm{VT}_{\text {total }}} 100\right)+\left(\frac{\mathrm{ABsT}_{\mathrm{i}}}{\mathrm{ABsT}_{\text {total }}} 100\right)}{3}$

Onde:

$\mathrm{IND}_{\mathrm{i}}=$ índice de importância da i-ésima espécie, em percentual

$\mathrm{NT}_{\mathrm{i}}=$ número total de árvores da i-ésima espécie

$\mathrm{NT}_{\text {total }}=$ número total de árvores da área inventariada

$\mathrm{VT}_{\mathrm{i}}=$ volume total da i-ésima espécie, $\mathrm{em} \mathrm{m}^{3}$

$\mathrm{VT}_{\text {total }}=$ volume total das árvores na área inventariada, $\mathrm{em}^{3}$

$\mathrm{ABsT}_{\mathrm{i}}=$ área basal total da i-ésima espécie, em $\mathrm{m}^{2}$

$\mathrm{ABsT}_{\text {total }}=$ área basal total da área inventariada, $\mathrm{em} \mathrm{m}^{2}$

Para as 12 propriedades foram inventariados 57 compartimentos de manejo, totalizando 206,8 hectares, correspondendo a $48 \%$ da área total sob manejo. A Tabela 1 apresenta a distribuição por propriedade, da área total, área sob manejo, área do compartimento, área inventariada e número de compartimentos inventariados.

\section{DETERMINAÇÃO DAS ESPÉCIES OCORRENTES}

A atribuição da denominação botânica das espécies, ou nome científico, foi baseada no trabalho de Araujo \& Silva (2000), no qual foram relacionadas 786 espécies florestais (lenhosas e não lenhosas) ocorrentes nos 10 principais inventários florestais já realizados no estado do Acre, sendo que as áreas desses inventários somadas cobrem 4.499.686 ha, ou 29,4\% da área total do estado.

Para o trabalho de Araujo \& Silva (2000), os nomes usuais e científicos foram aferidos no herbário da Fundação de Tecnologia do Estado do Acre - FUNTAC, utilizando-se de consultas à literatura de taxonomia vegetal, coleções de referência (exsicatas) e da larga experiência e conhecimento prático de seus mateiros e técnicos.

Vale informar que as espécies ocorrentes nas áreas inventariadas não foram identificadas em laboratório, ou seja, por meio de exsicatas (folhas, flores, frutos, etc.) ou através da anatomia da madeira, e sim, receberam a denominação botânica a partir do reconhecimento em campo pelo nome usual, fornecido por mateiros. Não obstante, os nomes usuais atribuídos estão em concordância com nomes usuais de espécies já identificadas no laboratório (herbário) da FUNTAC, uma vez que foram fornecidos, em boa parte, pelos mesmos mateiros. Esse aspecto 
Tabela 1 - Distribuição por propriedade da área total, área sob manejo, área do talhão de exploração, área inventariada a 100\% e número de talhões inventariados.

\begin{tabular}{|c|c|c|c|c|c|}
\hline \multirow{2}{*}{ PROP. } & \multicolumn{4}{|c|}{ ÁREA (ha) } & \multirow{2}{*}{-TALHÕES INVENTARIADOS } \\
\hline & TOTAL & SOB MANEJO & TALHÃO & INVENTARIADA & \\
\hline 1 & 72 & 36 & 3,6 & 18,0 & 5 \\
\hline 2 & 66 & 33 & 3,3 & 13,2 & 4 \\
\hline 3 & 72 & 36 & 3,6 & 18,0 & 5 \\
\hline 4 & 74 & 37 & 3,7 & 18,5 & 5 \\
\hline 5 & 66 & 33 & 3,3 & 13,2 & 4 \\
\hline 6 & 78 & 39 & 3,9 & 39,0 & 10 \\
\hline 7 & 72 & 36 & 3,6 & 14,4 & 4 \\
\hline 8 & 72 & 36 & 3,6 & 7,2 & 2 \\
\hline 9 & 72 & 36 & 3,6 & 10,8 & 3 \\
\hline 10 & 72 & 36 & 3,6 & 18,0 & 5 \\
\hline 11 & 76 & 38 & 3,8 & 19,0 & 5 \\
\hline 12 & 70 & 35 & 3,5 & 17,5 & 5 \\
\hline TOTAL & 862 & 431 & 43,1 & 206,8 & 57 \\
\hline MÉDIA & 72 & 36 & 3,6 & 17,2 & 4,75 \\
\hline
\end{tabular}

confere à denominação botânica dada às espécies credibilidade bastante satisfatória.

\section{RESULTADOS E DISCUSSÃO}

\section{INFORMAÇÕES DENDROMÉTRICAS}

A área total inventariada a 100\% (206,8 ha) revelou, para árvores com DAP $350,0 \mathrm{~cm}$, um número total de árvores (NT) de 3.518; abundância $(\mathrm{AB})$ de 17,01 árvores.ha ${ }^{-1}$; volume total (VT) de 21.667,41 $\mathrm{m}^{3}$; volume por hectare $(\mathrm{V})$ de 104,77 $\mathrm{m}^{3}$; área basal total $(\mathrm{ABs} T)$ de $1.413,77 \mathrm{~m}^{2}$; e, área basal por hectare (ABs) de $6,84 \mathrm{~m}^{2}$. A condição de aproveitamento da tora total foi de: $83,2 \%$ (2.926 árvores) com aproveitamento total; $14,0 \%$ (493 árvores) com aproveitamento parcial; e, 2,8\% (99 árvores) das toras foram qualificadas como sem aproveitamento.

A Tabela 2 apresenta os resultados do inventário florestal a $100 \%$ em separado para as 12 pequenas propriedades. Os resultados dendrométricos por espécie, incluindo o índice de importância da espécie (IND), são apresentados no Anexo 3.

Os valores médios dos parâmetros dendrométricos das propriedades, foram os seguintes: abundância $(\mathrm{AB})$ de 17,45 árvores.ha- ${ }^{-1}$; volume (V) de 109,47 $\mathrm{m}^{3} \cdot$ ha $^{-1}$; e área basal (ABs) de $7,13 \mathrm{~m}^{2} \cdot \mathrm{ha}^{-1}$. O coeficiente de variação percentual (CV\%) desses parâmetros (variando entre 15,6 e 18,2) demonstra uma relativa homogeneidade das áreas. Parte dessa variação, no entanto, pode ser atribuída ao fato de que houve, embora em escala reduzida em algumas das áreas, extração de madeira antes de iniciar o projeto de manejo florestal, o que alterou a ocorrência natural das árvores.

A condição 1 de aproveitamento da tora (aproveitamento total) apresentou um valor médio de $83,7 \%$, denotando um bom estado das toras para fins de processamento industrial. $\mathrm{O}$ baixo CV\% de 6,3 para esse dado indica homogeneidade das áreas quanto aos defeitos existentes nas suas árvores.

\section{ESPÉCIES OCORRENTES}

$\mathrm{Na}$ área inventariada, onde foi registrado um total de 3.518 árvores, foram reconhecidas, com base no nome usual de campo fornecido por mateiros, 204 espécies, pertencentes a 136 gêneros e a 43 famílias. A Figura 3 mostra a freqüência absoluta quanto ao número de espécies, gêneros e famílias.

Em número de espécies, as famílias mais importantes foram: 
Tabela 2 - Distribuição por propriedade do número total de árvores, abundância, volume total, volume por hectare, área basal total, área basal por hectare e condição de aproveitamento da tora das áreas inventariadas.

\begin{tabular}{|c|c|c|c|c|c|c|c|c|c|}
\hline \multirow{2}{*}{ PROP. } & \multirow{2}{*}{ NT } & \multirow{2}{*}{$\begin{array}{c}\mathbf{A B} \\
\left(\text { árvores.ha }^{-1} \text { ) }\right.\end{array}$} & \multirow{2}{*}{$\frac{\text { VT }}{\left(\mathrm{m}^{3}\right)}$} & \multirow{2}{*}{$\frac{\mathbf{V}}{\left(\mathrm{m}^{3} \cdot \mathrm{ha}^{-1}\right)}$} & \multirow{2}{*}{$\begin{array}{r}\text { ABsT } \\
\left(\mathrm{m}^{2}\right)\end{array}$} & \multirow{2}{*}{$\frac{\text { ABs }}{\left(m^{2} \cdot h a^{-1}\right)}$} & \multicolumn{3}{|c|}{ COND. DA TORA (\%) } \\
\hline & & & & & & & 1 & 2 & 3 \\
\hline 1 & 382 & 21,22 & 2222,34 & 123,46 & 145,87 & 8,10 & 81,2 & 13,6 & 5,2 \\
\hline 2 & 248 & 18,79 & 1602,96 & 121,44 & 104,09 & 7,89 & 79,0 & 18,2 & 2,8 \\
\hline 3 & 350 & 19,44 & 2253,24 & 125,18 & 146,38 & 8,13 & 84,0 & 11,1 & 4,9 \\
\hline 4 & 284 & 15,35 & 1873,10 & 101,25 & 121,40 & 6,56 & 76,7 & 18,7 & 4,6 \\
\hline 5 & 198 & 15,00 & 1038,56 & 78,68 & 68,96 & 5,22 & 89,4 & 9,6 & 1,0 \\
\hline 6 & 609 & 15,62 & 3235,42 & 82,96 & 214,49 & 5,50 & 74,6 & 23,4 & 2,0 \\
\hline 7 & 267 & 18,54 & 1591,89 & 110,55 & 104,22 & 7,24 & 85,4 & 12,4 & 2,2 \\
\hline 8 & 162 & 22,50 & 1095,83 & 152,20 & 70,86 & 9,84 & 84,0 & 15,4 & 0,6 \\
\hline 9 & 182 & 16,85 & 1221,52 & 113,10 & 79,04 & 7,32 & 81,9 & 16,5 & 1,6 \\
\hline 10 & 314 & 17,44 & 1924,67 & 106,93 & 125,64 & 6,98 & 86,6 & 9,6 & 3,8 \\
\hline 11 & 259 & 13,63 & 1830,29 & 96,33 & 117,87 & 6,20 & 91,1 & 8,1 & 0,8 \\
\hline 12 & 263 & 15,03 & 1777,59 & 101,58 & 114,95 & 6,57 & 90,1 & 7,6 & 2,3 \\
\hline TOTAL & 3518 & 17,01 & 21667,41 & 104,77 & 1413,77 & 6,84 & 83,2 & 14,0 & 2,8 \\
\hline MÉDIA & - & 17,45 & - & 109,47 & - & 7,13 & 83,7 & 13,7 & 2,7 \\
\hline (CV\%) & - & $(15,6)$ & - & $(18,2)$ & - & $(17,8)$ & $(6,3)$ & $(35,6)$ & $(61,2)$ \\
\hline
\end{tabular}

Onde: $\mathrm{NT}=$ número total de árvores; $\mathrm{AB}=$ abundância $\left(\right.$ árvores. $\left.\mathrm{ha}^{-1}\right) ; \mathrm{VT}=$ volume total $\left(\mathrm{m}^{3}\right) ; \mathrm{V}=$ volume por hectare $\left(\mathrm{m}^{3} \cdot \mathrm{ha}^{-1}\right) ; \mathrm{ABs} \mathrm{T}=$ área basal total $\left(\mathrm{m}^{2}\right) ; \mathrm{ABs}=$ área basal por hectare $\left(m^{2} \cdot \mathrm{ha}^{-1}\right)$

COND. DA TORA $(\%)=$ condição de aproveitamento da tora (percentual); 1 - tora com aproveitamento total; 2 - tora com aproveitamento parcial; 3 - tora sem aproveitamento

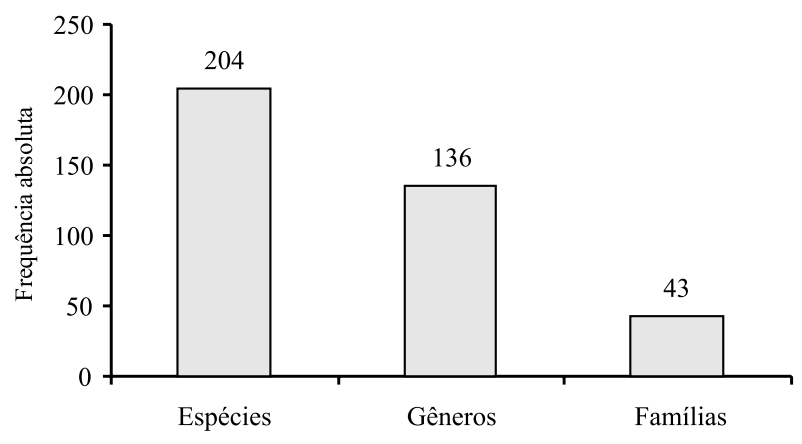

Figura 3 - Número de espécies, gêneros e famílias reconhecidos na área inventariada.

Caesalpiniaceae e Fabaceae (14 espécies cada); Mimosaceae (8 espécies); Moraceae (7 espécies); Annonaceae e Sapotaceae (6 espécies cada); Apocynaceae e Meliaceae (5 espécies cada); e, Bombacaceae, Euphorbiaceae, Lauraceae, Lecythidaceae e Rubiaceae (4 espécies cada). Os gêneros mais importantes foram: Inga (6 espécies); Brosimum e Ficus (5 espécies cada); Aspidosperma, Licania e Ocotea (4 espécies cada); Cariniana, Cecropia, Guarea, Ormosia, Parkia, Pourouma, Pouteria e Trichilia (3 espécies cada).
Cabe ressaltar que 98 (2,8\%) das 3.518 árvores ocorrentes não tiveram qualquer reconhecimento em campo, sendo consideradas desconhecidas. Desse modo, o número de árvores reconhecidas em campo totaliza 3.420. Essa informação revela que mesmo mateiros experientes, com grande vivência em áreas de florestas naturais, não são capazes de identificar 100\% da diversidade existente, demonstrando que não é simples a tarefa de identificar árvores, mesmo as de porte elevado.

Das 204 espécies reconhecidas em campo, 130 (63,7\%) foram identificadas botanicamente ao nível de espécie, 67 $(32,9 \%)$ somente ao nível de gênero, e, 7 (3,4\%) somente pela família (Figura 4).

A Tabela 3 apresenta a relação das 204 espécies reconhecidas em campo ocorrentes na área do inventário a $100 \%$, contendo o nome usual, nome científico (gênero e espécie) e família.

ÍNDICE DE IMPORTÂNCIA DAS ESPÉCIES (IND’S)

De acordo com o índice de importância da espécie (IND), calculado pela expressão (2), as cinco espécies de maior relevância ocorrentes na área inventariada foram, em ordem decrescente, as seguintes: Castanheira, Tauari, Cumaru-cetim, Seringueira e 


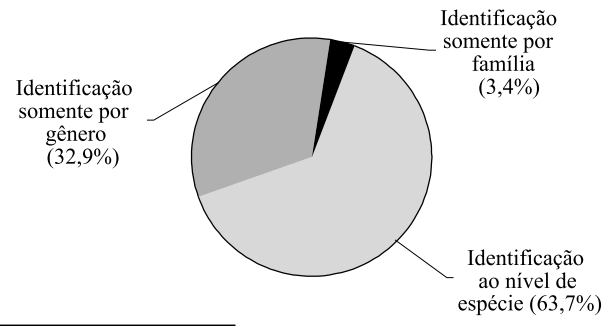

Figura 4 - Distribuição percentual das espécies quanto ao nível de identificação botânica a partir do reconhecimento em campo pelo nome usual.

Tabela 3 - Relação das espécies reconhecidas em campo na área inventariada.

\begin{tabular}{|c|c|c|c|}
\hline $\mathbf{N}$ & NOME USUAL & NOME CIENTÍFICO & FAMÍLIA \\
\hline 1 & Abiu & Pouteria sp. & SAPOTACEAE \\
\hline 2 & Abíu-bravo & Pouteria sp. & SAPOTACEAE \\
\hline 3 & Abiurana & Pouteria sp. & SAPOTACEAE \\
\hline 4 & Abiurana-abíu & Micropholis sp. & SAPOTACEAE \\
\hline 5 & Abiurana-de-massa & Urbenella sp. & SAPOTACEAE \\
\hline 6 & $\begin{array}{c}\text { Abiurana-folha-cinz- } \\
\text { enta }\end{array}$ & $\begin{array}{l}\text { Chrysophyllum } \\
\text { auratum Miq. }\end{array}$ & SAPOTACEAE \\
\hline 7 & Abiurana-preta & Ecclinusa sp. & SAPOTACEAE \\
\hline 8 & Abiurana-vermelha & $\begin{array}{l}\text { Chrysophyllum } \\
\text { prieurii }\end{array}$ & SAPOTACEAE \\
\hline 9 & Açacu & Hura crepitans L. & EUPHORBIACEAE \\
\hline 10 & Acariquara & $\begin{array}{c}\text { Minquartia } \\
\text { guianensis Aubl. }\end{array}$ & OLACACEAE \\
\hline 11 & Amapá & $\begin{array}{c}\text { Brosimum } \\
\text { parinarioides } \\
\text { Ducke }\end{array}$ & MORACEAE \\
\hline 12 & Amarelão & $\begin{array}{l}\text { Aspidosperma } \\
\text { vargasii } \mathrm{A} . \mathrm{DC} .\end{array}$ & APOCYNACEAE \\
\hline 13 & Andiroba & $\begin{array}{c}\text { Carapa } \\
\text { guianensis Aubl. }\end{array}$ & MELIACEAE \\
\hline 14 & Angelca & $\begin{array}{c}\text { Drypetes variabilis } \\
\text { Vitt. }\end{array}$ & EUPHORBIACEAE \\
\hline 15 & Angelca-preta & Cassipourea sp. & RHIZOPHORACEAE \\
\hline 16 & Angelim & $\begin{array}{l}\text { Hymenolobium } \\
\text { sp. }\end{array}$ & FABACEAE \\
\hline 17 & Angelim-amargoso & Vatairea sp. & FABACEAE \\
\hline 18 & Angelim-branco & Andira sp. & FABACEAE \\
\hline 19 & Angelim-da-mata & $\begin{array}{l}\text { Hymenolobium } \\
\text { excelsum Ducke }\end{array}$ & FABACEAE \\
\hline 20 & Angelim-paxiúba & ni & FABACEAE \\
\hline 21 & Angelim-pedra & ni & FABACEAE \\
\hline 22 & Angelim-preto & ni & FABACEAE \\
\hline 23 & Angelim-saião & $\begin{array}{l}\text { Parkia pendula } \\
\text { Benth. ex Walp. }\end{array}$ & MIMOSACEAE \\
\hline 24 & Angico & Parkia sp. & MIMOSACEAE \\
\hline 25 & Angico-amarelo & $\begin{array}{c}\text { Piptadenia } \\
\text { suaveolens Miq. }\end{array}$ & MIMOSACEAE \\
\hline 26 & Apuí & Fícus sp. & MORACEAE \\
\hline 27 & Apuí-amarelo & Ficus frondosa & MORACEAE \\
\hline 28 & Apuí-branco & $\begin{array}{c}\text { Ficus dusiaefolia } \\
\text { Schett. }\end{array}$ & MORACEAE \\
\hline 29 & Apuí-preto & Ficus sp. & MORACEAE \\
\hline
\end{tabular}

Tabela 3 - Continuação.

\begin{tabular}{|c|c|c|c|}
\hline $\mathrm{N}$ & NOME USUAL & NOME CIENTÍFICO & FAMÍLIA \\
\hline 30 & Araçá & Eugenia sp. & MYRTACEAE \\
\hline 31 & Arapari & $\begin{array}{l}\text { Macrolobium } \\
\text { acaciaefolium } \\
\text { Benth. }\end{array}$ & CAESALPINIACEAE \\
\hline 32 & Aroeira & $\begin{array}{c}\text { Astronium lecointei } \\
\text { Ducke }\end{array}$ & ANACARDIACEAE \\
\hline 33 & Ata & $\begin{array}{l}\text { Rollinia exsucca } \\
\text { (Dun.) DC. }\end{array}$ & ANNONACEAE \\
\hline 34 & Bacuri & $\begin{array}{c}\text { Rheedia brasiliensis } \\
\text { Mart. }\end{array}$ & CLUSIACEAE \\
\hline 35 & Bacuri-de-anta & $\begin{array}{c}\text { Platonia insignis } \\
\text { Mart. }\end{array}$ & CLUSIACEAE \\
\hline 36 & Bafo-de-boi & ni & CHRYSOBALANACEAE \\
\hline 37 & Bajão & Cassia sp. & CAESALPINIACEAE \\
\hline 38 & Bajinha & $\begin{array}{c}\text { Stryphnodendron } \\
\text { guianensis (Aubl.) } \\
\text { Benth. }\end{array}$ & MIMOSACEAE \\
\hline 39 & Bálsamo & $\begin{array}{c}\text { Myroxylon } \\
\text { balsamum Harms. }\end{array}$ & FABACEAE \\
\hline 40 & Breu-branco & $\begin{array}{c}\text { Protium hebetatum } \\
\text { D. Daly }\end{array}$ & BURSERACEAE \\
\hline 41 & Breu-manga & $\begin{array}{l}\text { Protium tenuifolium } \\
\text { (Engl.) Engl. }\end{array}$ & BURSERACEAE \\
\hline 42 & Breu-vermelho & $\begin{array}{c}\text { Tetragastris } \\
\text { altissima (Aubl.) } \\
\text { Swart. }\end{array}$ & BURSERACEAE \\
\hline 43 & Burra-leiteira & $\begin{array}{c}\text { Sapium marmieri } \\
\text { Hub. }\end{array}$ & EUPHORBIACEAE \\
\hline 44 & Cabelo-de-cutia & Banara nítida & FLACOURTIACEAE \\
\hline 45 & Café-bravo & Amaioua sp. & RUBIACEAE \\
\hline 46 & Caferana & Casearia sp. & FLACOURTIACEAE \\
\hline 47 & Cafezinho & $\begin{array}{l}\text { Ampelocera ruizii } \\
\text { Kuhlm. }\end{array}$ & ULMACEAE \\
\hline 48 & Cajuí & $\begin{array}{c}\text { Anacardium } \\
\text { giganteum } \\
\text { Hancock. }\end{array}$ & ANACARDIACEAE \\
\hline 49 & Cajuzinho & Cathedra acuminata & OLACACEAE \\
\hline 50 & Cambará & $\begin{array}{c}\text { Erisma uncinatum } \\
\text { Warm. }\end{array}$ & VOCHYSIACEAE \\
\hline 51 & Canafístula & $\begin{array}{c}\text { Schizolobium } \\
\text { amazonicum Hub. }\end{array}$ & CAESALPINIACEAE \\
\hline 52 & Capitiú & Mollinedia sp. & MONIMIACEAE \\
\hline 53 & Carapanaúba-amarela & $\begin{array}{l}\text { Aspidosperma } \\
\text { auriculatum }\end{array}$ & APOCYNACEAE \\
\hline 54 & Carapanaúba-preta & $\begin{array}{c}\text { Aspidosperma } \\
\text { oblongum A. DC. }\end{array}$ & APOCYNACEAE \\
\hline 55 & Caripé-branco & Hirtella sp. & CHRYSOBALANACEAE \\
\hline 56 & Caripé-roxo & Licania arbórea & CHRYSOBALANACEAE \\
\hline 57 & Caripé-vermelho & $\begin{array}{l}\text { Licania apetala } \\
\text { Fritsch. }\end{array}$ & CHRYSOBALANACEAE \\
\hline 58 & Castanheira & $\begin{array}{c}\text { Bertholletia excelsa } \\
\text { H. B. K. }\end{array}$ & LECYTHIDACEAE \\
\hline 59 & Catuaba & $\begin{array}{c}\text { Qualea tesmannii } \\
\text { Milldbr. }\end{array}$ & VOCHYSIACEAE \\
\hline
\end{tabular}


Tabela 3 - Continuação.

\begin{tabular}{|c|c|c|c|}
\hline $\mathbf{N}$ & NOME USUAL & NOME CIENTÍFICO & FAMÍLIA \\
\hline 60 & Catuaba-roxa & Qualea grandiflora & VOCHYSIACEAE \\
\hline 61 & Caucho & $\begin{array}{l}\text { Castilla ulei } \\
\text { Warburg. }\end{array}$ & MORACEAE \\
\hline 62 & Cedrinho & Vochysia sp. & VOCHYSIACEAE \\
\hline 63 & Cedro & Cedrela odorata L. & MELIACEAE \\
\hline 64 & Cedro-branco & $\begin{array}{l}\text { Cedrela fissilis } \\
\text { Ducke }\end{array}$ & MELIACEAE \\
\hline 65 & Cerejeira & $\begin{array}{c}\text { Torresea acreana } \\
\text { Ducke }\end{array}$ & FABACEAE \\
\hline 66 & Cernambi-de-índio & Drypetes sp. & EUPHORBIACEAE \\
\hline 67 & Coaçu & $\begin{array}{c}\text { Coccoloba } \\
\text { paniculata Meissn. }\end{array}$ & POLYGONACEAE \\
\hline 68 & Copaíba & $\begin{array}{c}\text { Copaifera multijuga } \\
\text { Hayne }\end{array}$ & CAESALPINIACEAE \\
\hline 69 & Copaíba-branca & Copaifera sp. & CAESALPINIACEAE \\
\hline 70 & Copinho & Lafoensia sp. & LYTHRACEAE \\
\hline 71 & Corrimboque & Cariniana sp. & LECYTHIDACEAE \\
\hline 72 & Corrimboque-duro & $\begin{array}{c}\text { Cariniana domestica } \\
\text { Mart. }\end{array}$ & LECYTHIDACEAE \\
\hline 73 & Cumaru-cetim & $\begin{array}{l}\text { Apuleia molaris } \\
\text { Spruce ex Benth. }\end{array}$ & CAESALPINIACEAE \\
\hline 74 & Cumaru-ferro & $\begin{array}{l}\text { Dipteryx odorata } \\
\text { (Aubl.) Willd }\end{array}$ & FABACEAE \\
\hline 75 & Cumarurana & $\begin{array}{l}\text { Dipteryx polyphylla } \\
\text { (Huber) Ducke }\end{array}$ & FABACEAE \\
\hline 76 & Cupuaçu-bravo & $\begin{array}{l}\text { Theobroma } \\
\text { obovatum }\end{array}$ & STERCULIACEAE \\
\hline 77 & Embiratanha & $\begin{array}{l}\text { Pseudobombax } \\
\text { coriacea }\end{array}$ & BOMBACACEAE \\
\hline 78 & Envira-amarela & Duguetia sp. & ANNONACEAE \\
\hline 79 & Envira-cajú & $\begin{array}{l}\text { Onychopetalum } \\
\text { Iucidum R. E. Fries }\end{array}$ & ANNONACEAE \\
\hline 80 & Envira-conduru & $\begin{array}{l}\text { Duguetia } \\
\text { macrophylla }\end{array}$ & ANNONACEAE \\
\hline 81 & Envira-piaca & ni & FABACEAE \\
\hline 82 & Envira-preta & $\begin{array}{l}\text { Ephedranthus } \\
\text { guianensis }\end{array}$ & ANNONACEAE \\
\hline 83 & Envira-sangue & Diplotropis sp. & FABACEAE \\
\hline 84 & Envira-vassourinha & Xylopia sp. & ANNONACEAE \\
\hline 85 & Espinheiro-preto & $\begin{array}{c}\text { Acacia pollyphylla } \\
\text { A. DC. }\end{array}$ & MIMOSACEAE \\
\hline 86 & Farinha-sêca & Celtis sp. & ULMACEAE \\
\hline 87 & Fava-amarela & Albizia sp. & MIMOSACEAE \\
\hline 88 & Fava-bolacha & Parkia sp. & MIMOSACEAE \\
\hline 89 & Fava-orelinha & $\begin{array}{c}\text { Enterolobium } \\
\text { schomburgkii Benth. }\end{array}$ & MIMOSACEAE \\
\hline 90 & Feijão-bravo & Ormosia sp. & FABACEAE \\
\hline 91 & Feijãozinho & Clitoria sp. & FABACEAE \\
\hline 92 & Gameleira & Ficus sp. & MORACEAE \\
\hline
\end{tabular}

Tabela 3 - Continuação.

\begin{tabular}{|c|c|c|c|}
\hline $\mathbf{N}$ & NOME USUAL & NOME CIENTÍFICO & FAMÍLIA \\
\hline 93 & Gogó-de-guariba & Leonia glycicarpa & VIOLACEAE \\
\hline 94 & Grão-de-galo & $\begin{array}{l}\text { Tabernaemontana } \\
\text { heptanphyllum }\end{array}$ & APOCYNACEAE \\
\hline 95 & Guaribeiro & $\begin{array}{l}\text { Phyllocarpus } \\
\text { riedellii Tul. }\end{array}$ & CAESALPINIACEAE \\
\hline 96 & Guariúba & $\begin{array}{c}\text { Clarisia racemosa } \\
\text { Ruiz et Pav. }\end{array}$ & MORACEAE \\
\hline 97 & Imbaúba & Cecropia sp. & CECROPIACEAE \\
\hline 98 & Imbaúba-branca & Cecropia leucoma & CECROPIACEAE \\
\hline 99 & Imbaúba-gigante & $\begin{array}{c}\text { Cecropia } \\
\text { sciadophylla }\end{array}$ & CECROPIACEAE \\
\hline 100 & Imbirindiba-amarela & Terminalia sp. & COMBRETACEAE \\
\hline 101 & Ingá & Inga sp. & MIMOSACEAE \\
\hline 102 & Ingá-de-várzea & Inga sp. & MIMOSACEAE \\
\hline 103 & Ingá-ferro & Inga sp. & MIMOSACEAE \\
\hline 104 & Ingá-mirim & Inga sp. & MIMOSACEAE \\
\hline 105 & Ingá-preta & Inga sp. & MIMOSACEAE \\
\hline 106 & Ingá-verde & Pithecellobium sp. & MIMOSACEAE \\
\hline 107 & Ingá-vermelha & Inga thibaudina DC. & MIMOSACEAE \\
\hline 108 & Inharé & $\begin{array}{l}\text { Brosimum } \\
\text { alicastrum Swartz. }\end{array}$ & MORACEAE \\
\hline 109 & Inharé-amarelo & Brosimum sp. & MORACEAE \\
\hline 110 & Ipê-amarelo & $\begin{array}{l}\text { Tabebuia serratifolia } \\
\text { (Vahl.) Nichols. }\end{array}$ & BIGNONIACEAE \\
\hline 111 & Itaúba & $\begin{array}{l}\text { Mezilaurus itauba } \\
\text { (Meissn.) Taub. }\end{array}$ & LAURACEAE \\
\hline 112 & Itaúba-preta & Siparuna sp. & MONIMIACEAE \\
\hline 113 & Itaubarana & Heisteria ovata & OLACACEAE \\
\hline 114 & Jacarandá & $\begin{array}{c}\text { Dalbergia } \\
\text { amazonicum }\end{array}$ & FABACEAE \\
\hline 115 & Jaracatiá & $\begin{array}{c}\text { Jaracatia spinosa } \\
\text { Aubl. }\end{array}$ & CARICACEAE \\
\hline 116 & Jatobá & $\begin{array}{c}\text { Hymenaea courbaril } \\
\text { L. }\end{array}$ & CAESALPINIACEAE \\
\hline 117 & Jenipapo & $\begin{array}{c}\text { Genipa americana } \\
\text { L. }\end{array}$ & RUBIACEAE \\
\hline 118 & Jequitibá & Cariniana sp. & LECYTHIDACEAE \\
\hline 119 & Jitó-branco & Guarea sp. & MELIACEAE \\
\hline 120 & Jitó-da-terra-firme & $\begin{array}{c}\text { Guarea pterorachis } \\
\text { Harms. }\end{array}$ & MELIACEAE \\
\hline 121 & Jitó-preto & $\begin{array}{c}\text { Guarea kunthiana A. } \\
\text { Juss. }\end{array}$ & MELIACEAE \\
\hline 122 & João-mole & Neea sp. & NYCTAGINACEAE \\
\hline 123 & Jutaí & $\begin{array}{c}\text { Hymenaea } \\
\text { oblongifolia Hub. }\end{array}$ & CAESALPINIACEAE \\
\hline 124 & Laranjinha & $\begin{array}{c}\text { Casearia } \\
\text { gossypiospermum }\end{array}$ & FLACOURTIACEAE \\
\hline 125 & Limãozinho & $\begin{array}{l}\text { Zanthoxylum } \\
\text { rhoifolium Lam. }\end{array}$ & RUTACEAE \\
\hline 126 & Louro & Ocotea sp. & LAURACEAE \\
\hline
\end{tabular}




\begin{tabular}{|c|c|c|c|}
\hline $\mathbf{N}$ & NOME USUAL & NOME CIENTÍFICO & FAMÍLIA \\
\hline 127 & Louro-abacate & Ocotea miriantha & LAURACEAE \\
\hline 128 & Louro-amarelo & Nectandra sp. & LAURACEAE \\
\hline 129 & Louro-aritu & Licaria aritu Ducke & LAURACEAE \\
\hline 130 & Louro-bosta & Ocotea sp. & LAURACEAE \\
\hline 131 & Louro-chumbo & Licaria sp. & LAURACEAE \\
\hline 132 & Louro-preto & $\begin{array}{l}\text { Ocotea neesiana } \\
\text { (Miq.) Kosterm. }\end{array}$ & LAURACEAE \\
\hline 133 & Maçaranduba & $\begin{array}{l}\text { Manilkara } \\
\text { surinamensis } \\
\text { (Miq.) Dub. }\end{array}$ & SAPOTACEAE \\
\hline 134 & Macucu-chiador & Licania sp. & CHRYSOBALANACEAE \\
\hline 135 & Macucu-sangue & $\begin{array}{l}\text { Licania latifolia } \\
\text { Benth. }\end{array}$ & CHRYSOBALANACEAE \\
\hline 136 & Malva-branca & Heliocarpus sp. & TILIACEAE \\
\hline 137 & $\begin{array}{l}\text { Malva-pente-de-mac- } \\
\text { aco }\end{array}$ & Apeiba timbourbou & TILIACEAE \\
\hline 138 & Manga-de-anta & Diclinanona sp. & ANNONACEAE \\
\hline 139 & Manitê & Brosimum uleanum & MORACEAE \\
\hline 140 & Maraximbé-vermelho & Trichilia pallida Sw. & MELIACEAE \\
\hline 141 & Marfim-fedorento & Rauwolfia sp. & APOCYNACEAE \\
\hline 142 & Marupá & $\begin{array}{l}\text { Jacaranda copaia } \\
\text { (Aubl.) D. Don. }\end{array}$ & BIGNONIACEAE \\
\hline 143 & Matamatá & $\begin{array}{l}\text { Eschweilera odora } \\
\text { (Poepp.) Miers. }\end{array}$ & LECYTHIDACEAE \\
\hline 144 & Mogno & $\begin{array}{c}\text { Swietenia } \\
\text { macrophylla King. }\end{array}$ & MELIACEAE \\
\hline 145 & Morototó & $\begin{array}{c}\text { Didymopanax } \\
\text { morototoni Dcne et } \\
\text { Planch. }\end{array}$ & ARALIACEAE \\
\hline 146 & Muirapiranga & Ormosia sp. & FABACEAE \\
\hline 147 & Muiraximbé-branco & Trichilia sp. & MELIACEAE \\
\hline 148 & Mulungu & Erythrina glauca & FABACEAE \\
\hline 149 & Mulungu-duro & Ormosia sp. & FABACEAE \\
\hline 150 & Murici & Trichilia sp. & MELIACEAE \\
\hline 151 & Mururé & $\begin{array}{c}\text { Brosimum } \\
\text { acutifolium Hub. }\end{array}$ & MORACEAE \\
\hline 152 & Mutamba & Guazuma sp. & STERCULIACEAE \\
\hline 153 & Pacote & $\begin{array}{l}\text { Cochlospermum } \\
\text { orinocense }\end{array}$ & COCHLOSPERMACEAE \\
\hline 154 & Pama-amarela & $\begin{array}{l}\text { Pseudolmedia } \\
\text { murure Standl. }\end{array}$ & MORACEAE \\
\hline 155 & Pama-caucho & $\begin{array}{l}\text { Perebea mollis (P. } \\
\text { G.) Hub. }\end{array}$ & MORACEAE \\
\hline 156 & Pama-preta & $\begin{array}{l}\text { Pseudolmedia } \\
\text { laevis }\end{array}$ & MORACEAE \\
\hline 157 & Pau-brasil & $\begin{array}{l}\text { Sickingia tinctoria } \\
\text { (H. B. K. ) K. Sch. }\end{array}$ & RUBIACEAE \\
\hline 158 & Pau-conserva & $\begin{array}{l}\text { Roupala montana } \\
\text { Aubl. }\end{array}$ & PROTEACEAE \\
\hline
\end{tabular}

\begin{tabular}{|c|c|c|c|}
\hline $\mathrm{N}$ & NOME USUAL & NOME CIENTÍFICO & FAMÍLIA \\
\hline 159 & Pau-d'arco-branco & $\begin{array}{l}\text { Sparattosperma } \\
\text { leucanthum K. } \\
\text { Schu. }\end{array}$ & BIGNONIACEAE \\
\hline 160 & Pau-de-lista & $\mathrm{ni}$ & MELIACEAE \\
\hline 161 & Pau-marfim & $\begin{array}{c}\text { Agonandra } \\
\text { brasiliensis Benth. } \\
\text { \& Hook. }\end{array}$ & OPILIACEAE \\
\hline 162 & Pau-sangue & $\begin{array}{c}\text { Pterocarpus rohrii } \\
\text { Vahl. }\end{array}$ & FABACEAE \\
\hline 163 & $\begin{array}{c}\text { Pau-sangue-casca-gr- } \\
\text { ossa }\end{array}$ & $\begin{array}{l}\text { - Platycyamus ulei } \\
\text { Harms. }\end{array}$ & FABACEAE \\
\hline 164 & Pente-de-macaco & $\begin{array}{c}\text { Apeiba echinata } \\
\text { Gaertn. }\end{array}$ & TILIACEAE \\
\hline 165 & Pereiro & $\begin{array}{c}\text { Aspidosperma } \\
\text { macrocarpon Mart. }\end{array}$ & APOCYNACEAE \\
\hline 166 & Pintadinho & $\begin{array}{c}\text { Poeppigia procera } \\
\text { Presl. }\end{array}$ & CAESALPINIACEAE \\
\hline 167 & Piqui & $\begin{array}{l}\text { Caryocar villosum } \\
\text { (Aubl.) Pers. }\end{array}$ & CARYOCARACEAE \\
\hline 168 & Piquiarana & $\begin{array}{l}\text { Caryocar glabrum } \\
\text { (Aubl.) Pers. Subsp } \\
\text { glabrum }\end{array}$ & CARYOCARACEAE \\
\hline 169 & Pitaíca & $\begin{array}{c}\text { Swartzia platygyne } \\
\text { Ducke }\end{array}$ & CAESALPINIACEAE \\
\hline 170 & Pororoca & $\begin{array}{l}\text { Martiodendron } \\
\text { elatum }\end{array}$ & CAESALPINIACEAE \\
\hline 171 & Quaruba & Erisma sp. & VOCHYSIACEAE \\
\hline 172 & Quina-quina-amarela & $\begin{array}{l}\text { Geissospermum } \\
\text { reticulatum }\end{array}$ & APOCYNACEAE \\
\hline 173 & Roxinho & Peltogyne sp. & CAESALPINIACEAE \\
\hline 174 & Samaúma & $\begin{array}{l}\text { Ceiba pentandra } \\
\text { (L.) Gaertn. }\end{array}$ & BOMBACACEAE \\
\hline 175 & Samaúma-barriguda & $\begin{array}{l}\text { Chorisia speciosa } \\
\text { St. Hill. }\end{array}$ & BOMBACACEAE \\
\hline 176 & Samaúma-preta & Ceiba samauma & BOMBACACEAE \\
\hline 177 & Sapota & $\begin{array}{l}\text { Matisia cf. cordata } \\
\text { Humb. \& Bonpl. }\end{array}$ & BOMBACACEAE \\
\hline 178 & Seringarana & Sapium sp. & EUPHORBIACEAE \\
\hline 179 & Seringueira & $\begin{array}{l}\text { Hevea brasiliensis } \\
\text { Muell. Arg. }\end{array}$ & EUPHORBIACEAE \\
\hline 180 & Sorva & $\begin{array}{c}\text { Couma macrocarpa } \\
\text { Barb. Rodr. }\end{array}$ & APOCYNACEAE \\
\hline 181 & Sucupira-amarela & $\begin{array}{c}\text { Vatairea sericea } \\
\text { Ducke }\end{array}$ & FABACEAE \\
\hline 182 & Sucupira-branca & ni & FABACEAE \\
\hline 183 & Sucupira-preta & $\begin{array}{c}\text { Diplotropis } \\
\text { purpurea (Rich.) } \\
\text { Amsh. }\end{array}$ & FABACEAE \\
\hline 184 & Taboarana & Alseis sp. & RUBIACEAE \\
\hline 185 & Tamarina & $\begin{array}{l}\text { Dialium guianense } \\
\text { (Aubl.) Sandw. }\end{array}$ & CAESALPINIACEAE \\
\hline 186 & Taperebá & $\begin{array}{l}\text { Spondias mombin } \\
\text { L. }\end{array}$ & ANACARDIACEAE \\
\hline
\end{tabular}




\begin{tabular}{|c|c|c|c|}
\hline $\mathbf{N}$ & NOME USUAL & NOME CIENTÍFICO & FAMÍLIA \\
\hline 187 & Tatajuba & $\begin{array}{l}\text { Maclura tinctoria } \\
\text { (L.) D.Dom ex } \\
\text { Steud. }\end{array}$ & MORACEAE \\
\hline 188 & Tauari & $\begin{array}{c}\text { Couratari } \\
\text { macrosperma }\end{array}$ & LECYTHIDACEAE \\
\hline 189 & Taxi-branco & $\begin{array}{c}\text { Sclerolobium } \\
\text { paniculatum Vogel }\end{array}$ & CAESALPINIACEAE \\
\hline 190 & Taxi-preto & $\begin{array}{c}\text { Tachigalia } \\
\text { paniculata Aubl. }\end{array}$ & CAESALPINIACEAE \\
\hline 191 & Taxi-vermelho & Sclerolobium sp. & CAESALPINIACEAE \\
\hline 192 & Taxirana & $\begin{array}{c}\text { Matayba } \\
\text { arborescens (Aubl.) } \\
\text { Radlk. }\end{array}$ & SAPINDACEAE \\
\hline 193 & Timbaúba & $\begin{array}{l}\text { Enterolobium } \\
\text { maximum Ducke }\end{array}$ & MIMOSACEAE \\
\hline 194 & Torém & Pourouma sp. & CECROPIACEAE \\
\hline 195 & Torém-de-lixa & Pourouma aspence & CECROPIACEAE \\
\hline 196 & Torém-imbaúba & Pourouma sp. & CECROPIACEAE \\
\hline 197 & Ucuuba-branca & $\begin{array}{l}\text { Osteophloeum } \\
\text { platyspermum (A. } \\
\text { DC.) Mart. }\end{array}$ & MYRISTICACEAE \\
\hline 198 & Ucuuba-preta & Virola multiflora & MYRISTICACEAE \\
\hline 199 & Ucuuba-punã & $\begin{array}{c}\text { Iryanthera juruensis } \\
\text { Warb. }\end{array}$ & MYRISTICACEAE \\
\hline 200 & Vela-branca & $\begin{array}{l}\text { Allophylus } \\
\text { floribundus (P. \& } \\
\text { E.) Radlk }\end{array}$ & SAPINDACEAE \\
\hline 201 & Violeta & $\begin{array}{l}\text { Platymiscium } \\
\text { duckei Hub. }\end{array}$ & FABACEAE \\
\hline 202 & Xixá & $\begin{array}{l}\text { Sterculia pruriens } \\
\text { (Aubl.) K. Schum. }\end{array}$ & STERCULIACEAE \\
\hline 203 & Xixá-casca-dura & Sterculia elata & STERCULIACEAE \\
\hline 204 & Xixuá & Maytenus sp. & CELASTRACEAE \\
\hline
\end{tabular}

Onde: $\mathrm{N}$ = número seqüencial; $\mathrm{ni}$ = não identificado

Cumaru-ferro. Essas espécies representam, sozinhas, um terço $(33,6 \%)$ do IND total (soma dos IND's das espécies). Para o total das 204 espécies, foi verificado que as 20 mais importantes (com maior IND), ou a décima parte do total de espécies, respondem por quase $60 \%$ do IND total (Figura 5), e, na outra ponta, as 20 menos importantes (com menor IND) representam apenas $0,355 \%$ do IND total.

A Castanheira é, com grande vantagem, a espécie que mais se destaca com um IND de $15,359 \%$, quase o triplo da segunda espécie mais importante, o Tauari, que apresentou um IND de $5,545 \%$. A Castanheira também é destaque devido à relevância da amêndoa (castanha) na alimentação das populaçōes tradicionais (seringueiros, índios, ribeirinhos, colonos, etc.), como fonte de renda, fator de contenção de emigração, entre outros aspectos. Cabe lembrar que a Castanheira e a Seringueira, outra espécie de elevado IND (4,248\%), são espécies protegidas por lei, não podendo, portanto, serem manejadas para fins madeireiros.

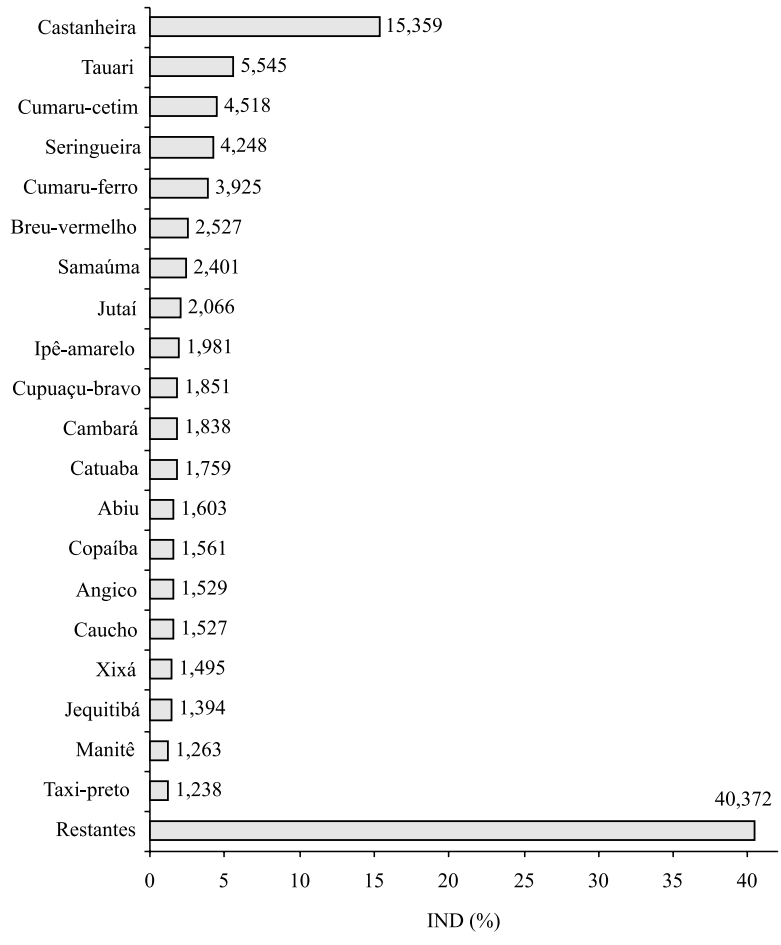

Figura 5 - As 20 principais espécies ocorrentes na área inventariada de acordo com 0 índice de importância da espécie (IND).

Observando o grupo das 20 espécies com maior IND, verificase que a maioria são espécies de madeira de uso comercial reconhecido para as mais diversas finalidades (móveis, pisos, vigamentos, painéis, etc.). Nesse grupo podem ser citadas as seguintes espécies com lugar consolidado no mercado de madeiras: Cumaru-cetim, Cumaru-ferro, Samaúma, Jutaí, Ipêamarelo, Cambará, Catuaba, Angico e Jequitibá. Essas nove espécies juntas somam um IND acima de $20 \%$ ou a quinta parte do total.

Do ponto de vista comercial, algumas das espécies do grupo das $20 \mathrm{com}$ maior IND podem ser consideradas emergentes, visto que são relativamente pouco conhecidas no mercado de madeiras. Entre estas estão o Breu-vermelho e o Tauari. No caso do Breu-vermelho, a espécie é em termos de número total de árvores $(\mathrm{NT}=124)$ a quinta mais importante, no entanto, por ser de menor porte físico em relação às demais (a espécie tem alta abundância na classe diamétrica situada entre 40,0 e 50,0 cm), possui menores volumes e área basal, o que a coloca em sexto lugar. O Tauari, cuja madeira apresenta excelentes propriedades tecnológicas, mostra-se uma espécie muito promissora, além de ser a segunda mais importante pelo critério do IND.

Ocorreram nas áreas muitas outras espécies de madeira conhecidas comercialmente, afora aquelas consideradas pouco conhecidas e que são potencialmente aptas a ingressar no mercado de madeira por possuírem boas propriedades tecnológicas. No 
entanto, essas espécies isoladamente, por apresentarem IND‘s baixos, não são muito representativas em termos quantitativos para o manejo.

De um modo geral, o inventário mostrou que uma parte significativa do estoque de madeira existente nas áreas é constituída por madeiras de valor comercial, apontando para a viabilidade econômica do manejo florestal, o que é de fundamental importância.

\section{CONCLUSÕES}

O acentuado desequilíbrio das espécies quanto aos IND‘s demonstra que nas florestas inventariadas, e por extensão a toda floresta amazônica, há expressiva concentração dos elementos dendrométricos, quer seja, poucas espécies reúnem a maior parte das árvores adultas e, conseqüentemente, a maior parte do volume de madeira. Deste modo, ao menos para florestas com estoque natural, é limitada a diversidade de espécies comerciais com grandes volumes de madeira disponíveis para o manejo florestal. Uma alternativa para as espécies de alto valor comercial que apresentam baixos IND's é conduzir tratamentos silviculturais, aliados à regeneração artificial, que aumentem suas participações.

O inventário florestal pré-exploratório, como etapa essencial de informações que possibilita todas as demais etapas seqüenciais do manejo sustentado de uma floresta, deve ser, no caso de pequenas áreas e na ótica técnico e operacional, acessível ao pequeno produtor, o qual, em regra, é desprovido de meios materiais e de conhecimentos educacionais elementares. No seu desenvolvimento, o método de inventário a $100 \%$ do PC Peixoto levou em conta a premissa de concepção simples, o que resultou na apropriação de competência por parte dos pequenos manejadores em executa-lo nas bases metodológicas estabelecidas.

\section{BIBLIOGRAFIA CITADA}

Araujo, H.J.B. 2002. Agrupamento das espécies madeireiras ocorrentes em pequenas áreas sob manejo florestal do Projeto de Colonização Pedro Peixoto (AC) por similaridade das propriedades fisicas $e$ mecânicas. Tese (Mestrado). Escola Superior de Agricultura "Luiz de Queiroz”, Universidade de São Paulo, Piracicaba. 168p.

Araujo, H.J.B. 1998. Índices técnicos da exploração e transformação madeireira em pequenas áreas sob manejo florestal no PC. Embrapa-CPAF/AC. Pedro Peixoto, Acre. 30p. (EMBRAPACPAF-Acre. Circular Técnica, 23).

Araujo, H.J.B.; Silva, I.G. 2000. Lista de espécies florestais do Acre (ocorrência com base em inventários florestais). Rio Branco: Embrapa-CPAF/AC. 77p. (EMBRAPA -CPAF/AC. Documentos, 48).

Araujo, H.J.B.; Oliveira, L.C. 1996. Manejo florestal sustentado em áreas de reserva legal de pequenas propriedades rurais do PC. Pedro Peixoto - Acre. Rio Branco: Embrapa-CPAF/AC. 7p. (EMBRAPA-CPAF/AC. Pesquisa em Andamento, 89).

Cavalcanti, T.J.S. 1994. Colonização no Acre: uma análise sócioeconômica do Projeto de Assentamento Dirigido "Pedro Peixoto". Dissertação (Mestrado) - Universidade Federal do Ceará - UFCE, Fortaleza. 196p.

Higuchi, N.; Vieira, G. 1990. Manejo sustentado da floresta tropical úmida de terra-firme na região de Manaus - um projeto de pesquisa do INPA. In: Congresso Florestal Brasileiro, 6. Anais. SBS/SBEF. Campos do Jordão. p.34-37.

Silva, J.N.M. 1990. Possibilidades da produção sustentada de madeira em floresta densa de terra-firme da Amazônia Brasileira. In: Congresso Florestal Brasileiro, 6. Anais. SBS/SBEF. Campos do Jordão. p.39-50.

Recebido em 08/09/2005

Aceito em 27/09/2006 
Anexo 1 - Modelo da ficha de campo utilizada no inventário florestal a 100\%.

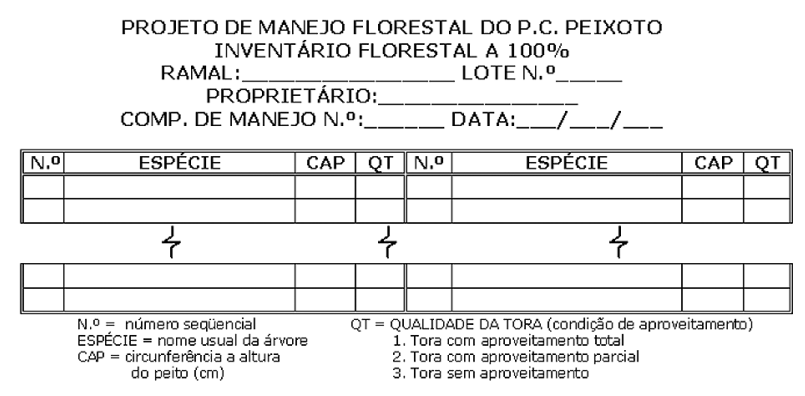

Anexo 2 - Exemplo de croqui utilizado no inventário florestal a 100\%: contendo a distribuição das árvores ocorrentes no compartimento de manejo.

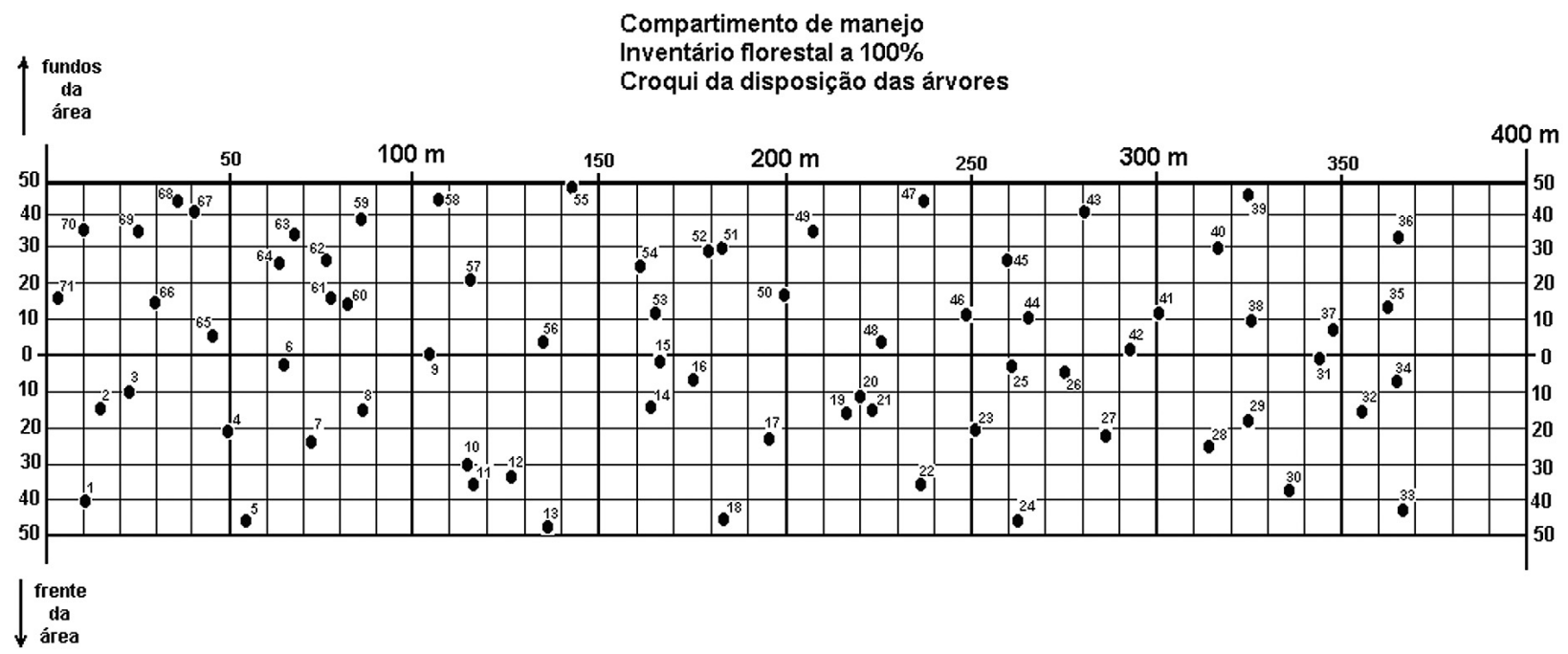


Anexo 3 - Resultado geral do inventário florestal a 100\%: distribuição, por espécie, de NT, AB, VT, V, AbsT, ABs, IND e condição de aproveitamento da tora.

\begin{tabular}{|c|c|c|c|c|c|c|c|c|c|c|c|}
\hline \multirow{2}{*}{$\mathbf{N}$} & \multirow{2}{*}{ ESPÉCIE } & \multirow{2}{*}{ NT } & \multirow{2}{*}{$\begin{array}{c}\text { AB } \\
\left({\left.\mathrm{N} . h a^{-1}\right)}^{-1}\right.\end{array}$} & \multirow{2}{*}{$\begin{array}{l}\text { VT } \\
\left(\mathrm{m}^{3}\right)\end{array}$} & \multirow{2}{*}{$\begin{array}{c}\mathbf{V} \\
\left(\mathrm{m}^{3} \cdot h \mathrm{~h}^{-1}\right)\end{array}$} & \multirow{2}{*}{$\begin{array}{l}\text { ABsT } \\
\left(\mathrm{m}^{2}\right)\end{array}$} & \multirow{2}{*}{$\begin{array}{c}\text { ABs } \\
\left(\mathrm{m}^{2} \cdot \mathrm{ha}^{-1}\right)\end{array}$} & \multirow{2}{*}{$\begin{array}{l}\text { IND } \\
(\%)\end{array}$} & \multicolumn{3}{|c|}{ COND. TORA (\%) } \\
\hline & & & & & & & & & 1 & 2 & 3 \\
\hline 1 & Abiu & 75 & 0,3627 & 280,9752 & 1,3587 & 19,5263 & 0,0944 & 1,603 & 84,0 & 13,3 & 2,7 \\
\hline 2 & Abíu-bravo & 5 & 0,0242 & 17,6032 & 0,0851 & 1,2356 & 0,0060 & 0,104 & 80,0 & 0,0 & 20,0 \\
\hline 3 & Abiurana & 16 & 0,0774 & 54,0818 & 0,2615 & 3,8217 & 0,0185 & 0,325 & 43,8 & 37,5 & 18,8 \\
\hline 4 & Abiurana-abíu & 1 & 0,0048 & 2,9122 & 0,0141 & 0,2114 & 0,0010 & 0,019 & 100,0 & 0,0 & 0,0 \\
\hline 5 & Abiurana-de-massa & 2 & 0,0097 & 12,3457 & 0,0597 & 0,8054 & 0,0039 & 0,057 & 50,0 & 50,0 & 0,0 \\
\hline 6 & Abiurana-folha-cinzenta & 5 & 0,0242 & 21,7490 & 0,1052 & 1,4788 & 0,0072 & 0,116 & 60,0 & 40,0 & 0,0 \\
\hline 7 & Abiurana-preta & 1 & 0,0048 & 3,1368 & 0,0152 & 0,2246 & 0,0011 & 0,020 & 100,0 & 0,0 & 0,0 \\
\hline 8 & Abiurana-vermelha & 3 & 0,0145 & 9,0703 & 0,0439 & 0,6539 & 0,0032 & 0,058 & 66,7 & 33,3 & 0,0 \\
\hline 9 & Açacu & 1 & 0,0048 & 3,0012 & 0,0145 & 0,2166 & 0,0010 & 0,019 & 0,0 & 100,0 & 0,0 \\
\hline 10 & Acariquara & 8 & 0,0387 & 25,1145 & 0,1214 & 1,7979 & 0,0087 & 0,157 & 100,0 & 0,0 & 0,0 \\
\hline 11 & Amapá & 9 & 0,0435 & 78,9076 & 0,3816 & 4,9938 & 0,0241 & 0,324 & 88,9 & 11,1 & 0,0 \\
\hline 12 & Amarelão & 33 & 0,1596 & 123,6824 & 0,5981 & 8,5946 & 0,0416 & 0,706 & 93,9 & 6,1 & 0,0 \\
\hline 13 & Andiroba & 18 & 0,0870 & 74,9538 & 0,3624 & 5,1273 & 0,0248 & 0,407 & 88,9 & 11,1 & 0,0 \\
\hline 14 & Angelca & 2 & 0,0097 & 7,2472 & 0,0350 & 0,5063 & 0,0024 & 0,042 & 50,0 & 0,0 & 50,0 \\
\hline 15 & Angelca-preta & 5 & 0,0242 & 25,5043 & 0,1233 & 1,6990 & 0,0082 & 0,127 & 60,0 & 20,0 & 20,0 \\
\hline 16 & Angelim & 40 & 0,1934 & 206,6579 & 0,9993 & 13,7460 & 0,0665 & 1,021 & 87,5 & 12,5 & 0,0 \\
\hline 17 & Angelim-amargoso & 28 & 0,1354 & 137,1945 & 0,6634 & 9,1842 & 0,0444 & 0,693 & 82,1 & 10,7 & 7,1 \\
\hline 18 & Angelim-branco & 9 & 0,0435 & 62,1991 & 0,3008 & 4,0139 & 0,0194 & 0,276 & 77,8 & 11,1 & 11,1 \\
\hline 19 & Angelim-da-mata & 3 & 0,0145 & 11,5046 & 0,0556 & 0,7966 & 0,0039 & 0,065 & 100,0 & 0,0 & 0,0 \\
\hline 20 & Angelim-paxiúba & 1 & 0,0048 & 10,7174 & 0,0518 & 0,6692 & 0,0032 & 0,042 & 100,0 & 0,0 & 0,0 \\
\hline 21 & Angelim-pedra & 3 & 0,0145 & 18,4236 & 0,0891 & 1,2025 & 0,0058 & 0,085 & 100,0 & 0,0 & 0,0 \\
\hline 22 & Angelim-preto & 3 & 0,0145 & 20,9430 & 0,1013 & 1,3502 & 0,0065 & 0,092 & 100,0 & 0,0 & 0,0 \\
\hline 23 & Angelim-saião & 6 & 0,0290 & 32,3915 & 0,1566 & 2,1436 & 0,0104 & 0,157 & 50,0 & 50,0 & 0,0 \\
\hline 24 & Angico & 42 & 0,2031 & 373,3946 & 1,8056 & 23,6073 & 0,1142 & 1,529 & 88,1 & 11,9 & 0,0 \\
\hline 25 & Angico-amarelo & 25 & 0,1209 & 148,2286 & 0,7168 & 9,7096 & 0,0470 & 0,694 & 100,0 & 0,0 & 0,0 \\
\hline 26 & Apuí & 27 & 0,1306 & 277,0772 & 1,3398 & 17,3486 & 0,0839 & 1,091 & 44,4 & 25,9 & 29,6 \\
\hline 27 & Apuí-amarelo & 6 & 0,0290 & 56,2877 & 0,2722 & 3,5451 & 0,0171 & 0,227 & 50,0 & 50,0 & 0,0 \\
\hline 28 & Apuí-branco & 3 & 0,0145 & 54,2561 & 0,2624 & 3,3042 & 0,0160 & 0,190 & 66,7 & 33,3 & 0,0 \\
\hline 29 & Apuí-preto & 2 & 0,0097 & 32,5326 & 0,1573 & 1,9894 & 0,0096 & 0,116 & 100,0 & 0,0 & 0,0 \\
\hline 30 & Araçá & 1 & 0,0048 & 3,2285 & 0,0156 & 0,2300 & 0,0011 & 0,020 & 100,0 & 0,0 & 0,0 \\
\hline 31 & Arapari & 3 & 0,0145 & 16,2818 & 0,0787 & 1,0768 & 0,0052 & 0,079 & 100,0 & 0,0 & 0,0 \\
\hline 32 & Aroeira & 30 & 0,1451 & 137,3357 & 0,6641 & 9,2736 & 0,0448 & 0,714 & 80,0 & 16,7 & 3,3 \\
\hline 33 & Ata & 6 & 0,0290 & 20,8082 & 0,1006 & 1,4641 & 0,0071 & 0,123 & 83,3 & 16,7 & 0,0 \\
\hline 34 & Bacuri & 1 & 0,0048 & 3,2285 & 0,0156 & 0,2300 & 0,0011 & 0,020 & 100,0 & 0,0 & 0,0 \\
\hline 35 & Bacuri-de-anta & 6 & 0,0290 & 32,9917 & 0,1595 & 2,1788 & 0,0105 & 0,159 & 100,0 & 0,0 & 0,0 \\
\hline 36 & Bafo-de-boi & 4 & 0,0193 & 18,2316 & 0,0882 & 1,2318 & 0,0060 & 0,095 & 100,0 & 0,0 & 0,0 \\
\hline 37 & Bajão & 3 & 0,0145 & 10,9404 & 0,0529 & 0,7634 & 0,0037 & 0,063 & 66,7 & 33,3 & 0,0 \\
\hline 38 & Bajinha & 1 & 0,0048 & 2,5252 & 0,0122 & 0,1887 & 0,0009 & 0,018 & 100,0 & 0,0 & 0,0 \\
\hline 39 & Bálsamo & 12 & 0,0580 & 44,4048 & 0,2147 & 3,0917 & 0,0150 & 0,255 & 83,3 & 8,3 & 8,3 \\
\hline 40 & Breu-branco & 1 & 0,0048 & 2,7808 & 0,0134 & 0,2037 & 0,0010 & 0,019 & 0,0 & 0,0 & 100,0 \\
\hline 41 & Breu-manga & 3 & 0,0145 & 9,9059 & 0,0479 & 0,7028 & 0,0034 & 0,060 & 100,0 & 0,0 & 0,0 \\
\hline 42 & Breu-vermelho & 124 & 0,5996 & 422,2093 & 2,0416 & 29,7998 & 0,1441 & 2,527 & 75,8 & 20,2 & 4,0 \\
\hline 43 & Burra-leiteira & 5 & 0,0242 & 18,6442 & 0,0902 & 1,2966 & 0,0063 & 0,107 & 100,0 & 0,0 & 0,0 \\
\hline 44 & Cabelo-de-cutia & 9 & 0,0435 & 34,5545 & 0,1671 & 2,3923 & 0,0116 & 0,195 & 77,8 & 22,2 & 0,0 \\
\hline
\end{tabular}


Anexo 3 - Continuação.

\begin{tabular}{|c|c|c|c|c|c|c|c|c|c|c|c|}
\hline \multirow{2}{*}{ N } & \multirow{2}{*}{ ESPÉCIE } & \multirow{2}{*}{ NT } & \multirow{2}{*}{$\begin{array}{c}\mathbf{A B} \\
\left(\mathrm{N} \cdot \mathrm{ha}^{-1}\right)\end{array}$} & \multirow{2}{*}{$\begin{array}{l}\text { VT } \\
\left(\mathrm{m}^{3}\right)\end{array}$} & \multirow{2}{*}{$\begin{array}{c}\mathbf{V} \\
\left(\mathrm{m}^{3} \cdot \mathrm{ha}^{-1}\right)\end{array}$} & \multirow{2}{*}{$\begin{array}{r}\text { ABsT } \\
\left(\mathrm{m}^{2}\right)\end{array}$} & \multirow{2}{*}{$\begin{array}{c}\text { ABs } \\
\left(\mathrm{m}^{2} . \mathrm{ha}^{-1}\right)\end{array}$} & \multirow{2}{*}{$\begin{array}{l}\text { IND } \\
(\%)\end{array}$} & \multicolumn{3}{|c|}{ COND. TORA (\%) } \\
\hline & & & & & & & & & 1 & 2 & 3 \\
\hline 45 & Café-bravo & 1 & 0,0048 & 5,1772 & 0,0250 & 0,3443 & 0,0017 & 0,026 & 100,0 & 0,0 & 0,0 \\
\hline 46 & Caferana & 2 & 0,0097 & 7,6205 & 0,0368 & 0,5282 & 0,0026 & 0,043 & 100,0 & 0,0 & 0,0 \\
\hline 47 & Cafezinho & 2 & 0,0097 & 17,7204 & 0,0857 & 1,1206 & 0,0054 & 0,073 & 50,0 & 50,0 & 0,0 \\
\hline 48 & Cajuí & 2 & 0,0097 & 30,7960 & 0,1489 & 1,8876 & 0,0091 & 0,111 & 50,0 & 0,0 & 50,0 \\
\hline 49 & Cajuzinho & 7 & 0,0338 & 43,2264 & 0,2090 & 2,8198 & 0,0136 & 0,199 & 85,7 & 14,3 & 0,0 \\
\hline 50 & Cambará & 56 & 0,2708 & 429,2131 & 2,0755 & 27,4498 & 0,1327 & 1,838 & 94,6 & 5,4 & 0,0 \\
\hline 51 & Canafístula & 1 & 0,0048 & 3,3681 & 0,0163 & 0,2382 & 0,0012 & 0,020 & 100,0 & 0,0 & 0,0 \\
\hline 52 & Capitiú & 1 & 0,0048 & 7,1222 & 0,0344 & 0,4584 & 0,0022 & 0,031 & 100,0 & 0,0 & 0,0 \\
\hline 53 & Carapanaúba-amarela & 31 & 0,1499 & 143,6429 & 0,6946 & 9,6843 & 0,0468 & 0,743 & 80,6 & 12,9 & 6,5 \\
\hline 54 & Carapanaúba-preta & 13 & 0,0629 & 48,2928 & 0,2335 & 3,3606 & 0,0163 & 0,277 & 69,2 & 30,8 & 0,0 \\
\hline 55 & Caripé-branco & 4 & 0,0193 & 15,8690 & 0,0767 & 1,0932 & 0,0053 & 0,088 & 75,0 & 25,0 & 0,0 \\
\hline 56 & Caripé-roxo & 1 & 0,0048 & 7,5847 & 0,0367 & 0,4855 & 0,0023 & 0,033 & 100,0 & 0,0 & 0,0 \\
\hline 57 & Caripé-vermelho & 5 & 0,0242 & 24,3225 & 0,1176 & 1,6296 & 0,0079 & 0,123 & 60,0 & 40,0 & 0,0 \\
\hline 58 & Castanheira & 327 & 1,5812 & 4089,8827 & 19,7770 & 253,1728 & 1,2242 & 15,359 & 97,6 & 2,4 & 0,0 \\
\hline 59 & Catuaba & 70 & 0,3385 & 352,1016 & 1,7026 & 23,4953 & 0,1136 & 1,759 & 82,9 & 14,3 & 2,9 \\
\hline 60 & Catuaba-roxa & 5 & 0,0242 & 34,2126 & 0,1654 & 2,2098 & 0,0107 & 0,152 & 100,0 & 0,0 & 0,0 \\
\hline 61 & Caucho & 72 & 0,3482 & 265,6360 & 1,2845 & 18,5044 & 0,0895 & 1,527 & 72,2 & 26,4 & 1,4 \\
\hline 62 & Cedrinho & 8 & 0,0387 & 33,8325 & 0,1636 & 2,3093 & 0,0112 & 0,182 & 87,5 & 12,5 & 0,0 \\
\hline 63 & Cedro & 21 & 0,1015 & 112,8606 & 0,5457 & 7,4725 & 0,0361 & 0,549 & 81,0 & 9,5 & 9,5 \\
\hline 64 & Cedro-branco & 7 & 0,0338 & 38,0818 & 0,1841 & 2,5179 & 0,0122 & 0,184 & 85,7 & 14,3 & 0,0 \\
\hline 65 & Cerejeira & 24 & 0,1161 & 124,8162 & 0,6036 & 8,2960 & 0,0401 & 0,615 & 87,5 & 12,5 & 0,0 \\
\hline 66 & Cernambi-de-índio & 35 & 0,1692 & 162,7523 & 0,7870 & 10,9674 & 0,0530 & 0,841 & 91,4 & 8,6 & 0,0 \\
\hline 67 & Coaçu & 2 & 0,0097 & 11,4530 & 0,0554 & 0,7530 & 0,0036 & 0,054 & 0,0 & 50,0 & 50,0 \\
\hline 68 & Copaíba & 51 & 0,2466 & 352,3753 & 1,7039 & 22,7400 & 0,1100 & 1,561 & 92,2 & 5,9 & 2,0 \\
\hline 69 & Copaíba-branca & 1 & 0,0048 & 7,0572 & 0,0341 & 0,4546 & 0,0022 & 0,031 & 100,0 & 0,0 & 0,0 \\
\hline 70 & Copinho & 4 & 0,0193 & 19,4295 & 0,0940 & 1,3020 & 0,0063 & 0,098 & 100,0 & 0,0 & 0,0 \\
\hline 71 & Corrimboque & 5 & 0,0242 & 71,4352 & 0,3454 & 4,3931 & 0,0212 & 0,261 & 100,0 & 0,0 & 0,0 \\
\hline 72 & Corrimboque-duro & 2 & 0,0097 & 20,7180 & 0,1002 & 1,2965 & 0,0063 & 0,081 & 100,0 & 0,0 & 0,0 \\
\hline 73 & Cumaru-cetim & 126 & 0,6093 & 1096,6535 & 5,3030 & 69,4411 & 0,3358 & 4,518 & 73,0 & 19,0 & 7,9 \\
\hline 74 & Cumaru-ferro & 113 & 0,5464 & 939,9317 & 4,5451 & 59,7213 & 0,2888 & 3,925 & 84,1 & 14,2 & 1,8 \\
\hline 75 & Cumarurana & 2 & 0,0097 & 9,9943 & 0,0483 & 0,6674 & 0,0032 & 0,050 & 100,0 & 0,0 & 0,0 \\
\hline 76 & Cupuaçu-bravo & 70 & 0,3385 & 383,5778 & 1,8548 & 25,3416 & 0,1225 & 1,851 & 67,1 & 30,0 & 2,9 \\
\hline 77 & Embiratanha & 1 & 0,0048 & 3,2285 & 0,0156 & 0,2300 & 0,0011 & 0,020 & 100,0 & 0,0 & 0,0 \\
\hline 78 & Envira-amarela & 1 & 0,0048 & 4,1027 & 0,0198 & 0,2813 & 0,0014 & 0,022 & 100,0 & 0,0 & 0,0 \\
\hline 79 & Envira-cajú & 1 & 0,0048 & 2,3602 & 0,0114 & 0,1790 & 0,0009 & 0,017 & 100,0 & 0,0 & 0,0 \\
\hline 80 & Envira-conduru & 1 & 0,0048 & 6,4845 & 0,0314 & 0,4210 & 0,0020 & 0,029 & 0,0 & 100,0 & 0,0 \\
\hline 81 & Envira-piaca & 2 & 0,0097 & 7,4338 & 0,0359 & 0,5173 & 0,0025 & 0,043 & 100,0 & 0,0 & 0,0 \\
\hline 82 & Envira-preta & 2 & 0,0097 & 13,8781 & 0,0671 & 0,8952 & 0,0043 & 0,061 & 100,0 & 0,0 & 0,0 \\
\hline 83 & Envira-sangue & 4 & 0,0193 & 14,5427 & 0,0703 & 1,0154 & 0,0049 & 0,084 & 100,0 & 0,0 & 0,0 \\
\hline 84 & Envira-vassourinha & 2 & 0,0097 & 6,0230 & 0,0291 & 0,4345 & 0,0021 & 0,038 & 100,0 & 0,0 & 0,0 \\
\hline 85 & Espinheiro-preto & 47 & 0,2273 & 170,5330 & 0,8246 & 11,9112 & 0,0576 & 0,989 & 63,8 & 31,9 & 4,3 \\
\hline 86 & Farinha-sêca & 3 & 0,0145 & 8,0722 & 0,0390 & 0,5953 & 0,0029 & 0,055 & 33,3 & 66,7 & 0,0 \\
\hline 87 & Fava-amarela & 2 & 0,0097 & 16,6513 & 0,0805 & 1,0579 & 0,0051 & 0,070 & 50,0 & 50,0 & 0,0 \\
\hline 88 & Fava-bolacha & 1 & 0,0048 & 14,0820 & 0,0681 & 0,8666 & 0,0042 & 0,052 & 100,0 & 0,0 & 0,0 \\
\hline
\end{tabular}


Anexo 3 - Continuação.

\begin{tabular}{|c|c|c|c|c|c|c|c|c|c|c|c|}
\hline \multirow{2}{*}{$\mathbf{N}$} & \multirow{2}{*}{ ESPÉCIE } & \multirow{2}{*}{ NT } & \multirow{2}{*}{$\begin{array}{c}\mathbf{A B} \\
\left(\mathrm{N}^{-h a^{-1}}\right)\end{array}$} & \multirow{2}{*}{$\begin{array}{l}\text { VT } \\
\left(\mathrm{m}^{3}\right)\end{array}$} & \multirow{2}{*}{$\begin{array}{c}\mathbf{V} \\
\left(\mathrm{m}^{3} \cdot \mathrm{ha}^{-1}\right)\end{array}$} & \multirow{2}{*}{$\begin{array}{l}\text { ABsT } \\
\left(\mathrm{m}^{2}\right)\end{array}$} & \multirow{2}{*}{$\begin{array}{c}\text { ABs } \\
\left(m^{2} \cdot h a^{-1}\right)\end{array}$} & \multirow{2}{*}{$\begin{array}{l}\text { IND } \\
(\%)\end{array}$} & \multicolumn{3}{|c|}{ COND. TORA (\%) } \\
\hline & & & & & & & & & 1 & 2 & 3 \\
\hline 89 & Fava-orelinha & 21 & 0,1015 & 116,9946 & 0,5657 & 7,7153 & 0,0373 & 0,561 & 81,0 & 9,5 & 9,5 \\
\hline 90 & Feijão-bravo & 1 & 0,0048 & 3,7033 & 0,0179 & 0,2578 & 0,0012 & 0,021 & 0,0 & 0,0 & 100,0 \\
\hline 91 & Feijãozinho & 1 & 0,0048 & 5,2907 & 0,0256 & 0,3509 & 0,0017 & 0,026 & 0,0 & 0,0 & 100,0 \\
\hline 92 & Gameleira & 6 & 0,0290 & 49,8494 & 0,2411 & 3,1676 & 0,0153 & 0,208 & 50,0 & 50,0 & 0,0 \\
\hline 93 & Gogó-de-guariba & 1 & 0,0048 & 4,5728 & 0,0221 & 0,3088 & 0,0015 & 0,024 & 100,0 & 0,0 & 0,0 \\
\hline 94 & Grão-de-galo & 5 & 0,0242 & 15,6784 & 0,0758 & 1,1227 & 0,0054 & 0,098 & 80,0 & 20,0 & 0,0 \\
\hline 95 & Guaribeiro & 15 & 0,0725 & 63,2525 & 0,3059 & 4,3193 & 0,0209 & 0,341 & 86,7 & 13,3 & 0,0 \\
\hline 96 & Guariúba & 54 & 0,2611 & 230,3540 & 1,1139 & 15,7045 & 0,0759 & 1,236 & 87,0 & 11,1 & 1,9 \\
\hline 97 & Imbaúba & 1 & 0,0048 & 2,7808 & 0,0134 & 0,2037 & 0,0010 & 0,019 & 100,0 & 0,0 & 0,0 \\
\hline 98 & Imbaúba-branca & 1 & 0,0048 & 2,3602 & 0,0114 & 0,1790 & 0,0009 & 0,017 & 100,0 & 0,0 & 0,0 \\
\hline 99 & Imbaúba-gigante & 5 & 0,0242 & 13,3331 & 0,0645 & 0,9850 & 0,0048 & 0,091 & 100,0 & 0,0 & 0,0 \\
\hline 100 & Imbirindiba-amarela & 37 & 0,1789 & 228,8270 & 1,1065 & 14,9247 & 0,0722 & 1,054 & 81,1 & 16,2 & 2,7 \\
\hline 101 & Ingá & 6 & 0,0290 & 21,8001 & 0,1054 & 1,5222 & 0,0074 & 0,126 & 100,0 & 0,0 & 0,0 \\
\hline 102 & Ingá-de-várzea & 1 & 0,0048 & 4,1539 & 0,0201 & 0,2843 & 0,0014 & 0,023 & 100,0 & 0,0 & 0,0 \\
\hline 103 & Ingá-ferro & 7 & 0,0338 & 28,5815 & 0,1382 & 1,9607 & 0,0095 & 0,157 & 85,7 & 14,3 & 0,0 \\
\hline 104 & Ingá-mirim & 2 & 0,0097 & 5,6530 & 0,0273 & 0,4128 & 0,0020 & 0,037 & 50,0 & 50,0 & 0,0 \\
\hline 105 & Ingá-preta & 3 & 0,0145 & 10,2138 & 0,0494 & 0,7209 & 0,0035 & 0,061 & 100,0 & 0,0 & 0,0 \\
\hline 106 & Ingá-verde & 1 & 0,0048 & 2,3602 & 0,0114 & 0,1790 & 0,0009 & 0,017 & 0,0 & 100,0 & 0,0 \\
\hline 107 & Ingá-vermelha & 25 & 0,1209 & 125,1936 & 0,6054 & 8,3584 & 0,0404 & 0,627 & 60,0 & 32,0 & 8,0 \\
\hline 108 & Inharé & 15 & 0,0725 & 56,8123 & 0,2747 & 3,9412 & 0,0191 & 0,322 & 53,3 & 33,3 & 13,3 \\
\hline 109 & Inharé-amarelo & 1 & 0,0048 & 4,4137 & 0,0213 & 0,2995 & 0,0014 & 0,023 & 100,0 & 0,0 & 0,0 \\
\hline 110 & Ipê-amarelo & 85 & 0,4110 & 374,4814 & 1,8108 & 25,4173 & 0,1229 & 1,981 & 89,4 & 10,6 & 0,0 \\
\hline 111 & Itaúba & 26 & 0,1257 & 143,5029 & 0,6939 & 9,4731 & 0,0458 & 0,690 & 92,3 & 3,8 & 3,8 \\
\hline 112 & Itaúba-preta & 1 & 0,0048 & 2,3602 & 0,0114 & 0,1790 & 0,0009 & 0,017 & 100,0 & 0,0 & 0,0 \\
\hline 113 & Itaubarana & 3 & 0,0145 & 8,7784 & 0,0424 & 0,6367 & 0,0031 & 0,057 & 100,0 & 0,0 & 0,0 \\
\hline 114 & Jacarandá & 1 & 0,0048 & 2,7808 & 0,0134 & 0,2037 & 0,0010 & 0,019 & 100,0 & 0,0 & 0,0 \\
\hline 115 & Jaracatiá & 5 & 0,0242 & 17,6560 & 0,0854 & 1,2386 & 0,0060 & 0,104 & 100,0 & 0,0 & 0,0 \\
\hline 116 & Jatobá & 4 & 0,0193 & 27,4635 & 0,1328 & 1,7734 & 0,0086 & 0,122 & 100,0 & 0,0 & 0,0 \\
\hline 117 & Jenipapo & 1 & 0,0048 & 2,7808 & 0,0134 & 0,2037 & 0,0010 & 0,019 & 100,0 & 0,0 & 0,0 \\
\hline 118 & Jequitibá & 25 & 0,1209 & 387,9611 & 1,8760 & 23,7710 & 0,1149 & 1,394 & 100,0 & 0,0 & 0,0 \\
\hline 119 & Jitó-branco & 33 & 0,1596 & 172,8955 & 0,8361 & 11,4811 & 0,0555 & 0,849 & 84,8 & 12,1 & 3,0 \\
\hline 120 & Jitó-da-terra-firme & 4 & 0,0193 & 17,5871 & 0,0850 & 1,1940 & 0,0058 & 0,093 & 100,0 & 0,0 & 0,0 \\
\hline 121 & Jitó-preto & 1 & 0,0048 & 3,0913 & 0,0149 & 0,2219 & 0,0011 & 0,019 & 100,0 & 0,0 & 0,0 \\
\hline 122 & João-mole & 3 & 0,0145 & 9,0554 & 0,0438 & 0,6530 & 0,0032 & 0,058 & 33,3 & 66,7 & 0,0 \\
\hline 123 & Jutaí & 84 & 0,4062 & 407,3806 & 1,9699 & 27,3059 & 0,1320 & 2,066 & 95,2 & 4,8 & 0,0 \\
\hline 124 & Laranjinha & 3 & 0,0145 & 7,7535 & 0,0375 & 0,5765 & 0,0028 & 0,054 & 100,0 & 0,0 & 0,0 \\
\hline 125 & Limãozinho & 3 & 0,0145 & 9,2378 & 0,0447 & 0,6637 & 0,0032 & 0,058 & 100,0 & 0,0 & 0,0 \\
\hline 126 & Louro & 5 & 0,0242 & 30,8726 & 0,1493 & 2,0138 & 0,0097 & 0,142 & 100,0 & 0,0 & 0,0 \\
\hline 127 & Louro-abacate & 1 & 0,0048 & 2,7808 & 0,0134 & 0,2037 & 0,0010 & 0,019 & 0,0 & 100,0 & 0,0 \\
\hline 128 & Louro-amarelo & 1 & 0,0048 & 4,1539 & 0,0201 & 0,2843 & 0,0014 & 0,023 & 100,0 & 0,0 & 0,0 \\
\hline 129 & Louro-aritu & 7 & 0,0338 & 23,4202 & 0,1133 & 1,6580 & 0,0080 & 0,141 & 71,4 & 28,6 & 0,0 \\
\hline 130 & Louro-bosta & 1 & 0,0048 & 2,3602 & 0,0114 & 0,1790 & 0,0009 & 0,017 & 100,0 & 0,0 & 0,0 \\
\hline 131 & Louro-chumbo & 6 & 0,0290 & 22,1555 & 0,1071 & 1,5432 & 0,0075 & 0,127 & 66,7 & 16,7 & 16,7 \\
\hline 132 & Louro-preto & 1 & 0,0048 & 3,1368 & 0,0152 & 0,2246 & 0,0011 & 0,020 & 0,0 & 100,0 & 0,0 \\
\hline
\end{tabular}


Anexo 3 - Continuação.

\begin{tabular}{|c|c|c|c|c|c|c|c|c|c|c|c|}
\hline \multirow{2}{*}{$\mathbf{N}$} & \multirow{2}{*}{ ESPÉCIE } & \multirow{2}{*}{ NT } & \multirow{2}{*}{$\begin{array}{c}\mathbf{A B} \\
\left(\mathrm{N}^{-h^{-1}}\right)\end{array}$} & \multirow{2}{*}{$\begin{array}{l}\text { VT } \\
\left(\mathrm{m}^{3}\right)\end{array}$} & \multirow{2}{*}{$\begin{array}{c}\mathbf{V} \\
\left(\mathrm{m}^{3} \cdot \mathrm{ha}^{-1}\right)\end{array}$} & \multirow{2}{*}{$\begin{array}{r}\text { ABsT } \\
\left(\mathrm{m}^{2}\right)\end{array}$} & \multirow{2}{*}{$\begin{array}{c}\text { ABs } \\
\left(\mathrm{m}^{2} \cdot \mathrm{ha}^{-1}\right)\end{array}$} & \multirow{2}{*}{$\begin{array}{l}\text { IND } \\
(\%)\end{array}$} & \multicolumn{3}{|c|}{ COND. TORA (\%) } \\
\hline & & & & & & & & & 1 & 2 & 3 \\
\hline 133 & Maçaranduba & 41 & 0,1983 & 216,7616 & 1,0482 & 14,3793 & 0,0695 & 1,061 & 95,1 & 4,9 & 0,0 \\
\hline 134 & Macucu-chiador & 1 & 0,0048 & 2,7808 & 0,0134 & 0,2037 & 0,0010 & 0,019 & 0,0 & 100,0 & 0,0 \\
\hline 135 & Macucu-sangue & 1 & 0,0048 & 3,8016 & 0,0184 & 0,2636 & 0,0013 & 0,022 & 100,0 & 0,0 & 0,0 \\
\hline 136 & Malva-branca & 3 & 0,0145 & 9,1292 & 0,0441 & 0,6572 & 0,0032 & 0,058 & 66,7 & 33,3 & 0,0 \\
\hline 137 & Malva-pente-de-macaco & 16 & 0,0774 & 53,2940 & 0,2577 & 3,7757 & 0,0183 & 0,323 & 62,5 & 37,5 & 0,0 \\
\hline 138 & Manga-de-anta & 6 & 0,0290 & 25,6639 & 0,1241 & 1,7489 & 0,0085 & 0,138 & 50,0 & 50,0 & 0,0 \\
\hline 139 & Manitê & 43 & 0,2079 & 278,7007 & 1,3477 & 18,0936 & 0,0875 & 1,263 & 81,4 & 18,6 & 0,0 \\
\hline 140 & Maraximbé-vermelho & 1 & 0,0048 & 3,2285 & 0,0156 & 0,2300 & 0,0011 & 0,020 & 0,0 & 0,0 & 100,0 \\
\hline 141 & Marfim-fedorento & 1 & 0,0048 & 4,4665 & 0,0216 & 0,3026 & 0,0015 & 0,023 & 100,0 & 0,0 & 0,0 \\
\hline 142 & Marupá & 48 & 0,2321 & 187,2878 & 0,9056 & 12,9346 & 0,0625 & 1,048 & 89,6 & 10,4 & 0,0 \\
\hline 143 & Matamatá & 11 & 0,0532 & 40,3388 & 0,1951 & 2,8127 & 0,0136 & 0,233 & 63,6 & 36,4 & 0,0 \\
\hline 144 & Mogno & 1 & 0,0048 & 24,5097 & 0,1185 & 1,4782 & 0,0071 & 0,082 & 100,0 & 0,0 & 0,0 \\
\hline 145 & Morototó & 1 & 0,0048 & 3,7523 & 0,0181 & 0,2607 & 0,0013 & 0,021 & 100,0 & 0,0 & 0,0 \\
\hline 146 & Muirapiranga & 1 & 0,0048 & 5,3478 & 0,0259 & 0,3543 & 0,0017 & 0,026 & 100,0 & 0,0 & 0,0 \\
\hline 147 & Muiraximbé-branco & 2 & 0,0097 & 10,8391 & 0,0524 & 0,7169 & 0,0035 & 0,053 & 50,0 & 0,0 & 50,0 \\
\hline 148 & Mulungu & 1 & 0,0048 & 2,4010 & 0,0116 & 0,1814 & 0,0009 & 0,017 & 100,0 & 0,0 & 0,0 \\
\hline 149 & Mulungu-duro & 1 & 0,0048 & 3,2285 & 0,0156 & 0,2300 & 0,0011 & 0,020 & 100,0 & 0,0 & 0,0 \\
\hline 150 & Murici & 2 & 0,0097 & 6,0528 & 0,0293 & 0,4363 & 0,0021 & 0,039 & 100,0 & 0,0 & 0,0 \\
\hline 151 & Mururé & 5 & 0,0242 & 18,0346 & 0,0872 & 1,2610 & 0,0061 & 0,105 & 60,0 & 40,0 & 0,0 \\
\hline 152 & Mutamba & 3 & 0,0145 & 27,0782 & 0,1309 & 1,7101 & 0,0083 & 0,110 & 100,0 & 0,0 & 0,0 \\
\hline 153 & Pacote & 1 & 0,0048 & 5,5208 & 0,0267 & 0,3644 & 0,0018 & 0,027 & 100,0 & 0,0 & 0,0 \\
\hline 154 & Pama-amarela & 18 & 0,0870 & 64,8687 & 0,3137 & 4,5356 & 0,0219 & 0,377 & 72,2 & 22,2 & 5,6 \\
\hline 155 & Pama-caucho & 2 & 0,0097 & 6,2046 & 0,0300 & 0,4452 & 0,0022 & 0,039 & 100,0 & 0,0 & 0,0 \\
\hline 156 & Pama-preta & 39 & 0,1886 & 143,8330 & 0,6955 & 10,0201 & 0,0485 & 0,827 & 71,8 & 23,1 & 5,1 \\
\hline 157 & Pau-brasil & 1 & 0,0048 & 2,3602 & 0,0114 & 0,1790 & 0,0009 & 0,017 & 100,0 & 0,0 & 0,0 \\
\hline 158 & Pau-conserva & 2 & 0,0097 & 5,6132 & 0,0271 & 0,4105 & 0,0020 & 0,037 & 50,0 & 50,0 & 0,0 \\
\hline 159 & Pau-d'arco-branco & 2 & 0,0097 & 11,6625 & 0,0564 & 0,7653 & 0,0037 & 0,055 & 50,0 & 50,0 & 0,0 \\
\hline 160 & Pau-de-lista & 1 & 0,0048 & 5,0091 & 0,0242 & 0,3344 & 0,0016 & 0,025 & 100,0 & 0,0 & 0,0 \\
\hline 161 & Pau-marfim & 5 & 0,0242 & 23,4819 & 0,1135 & 1,5803 & 0,0076 & 0,121 & 100,0 & 0,0 & 0,0 \\
\hline 162 & Pau-sangue & 22 & 0,1064 & 97,3393 & 0,4707 & 6,6027 & 0,0319 & 0,514 & 63,6 & 22,7 & 13,6 \\
\hline 163 & Pau-sangue-casca-grossa & 2 & 0,0097 & 9,3995 & 0,0455 & 0,6325 & 0,0031 & 0,048 & 0,0 & 50,0 & 50,0 \\
\hline 164 & Pente-de-macaco & 4 & 0,0193 & 14,7856 & 0,0715 & 1,0297 & 0,0050 & 0,085 & 75,0 & 25,0 & 0,0 \\
\hline 165 & Pereiro & 6 & 0,0290 & 62,2655 & 0,3011 & 3,8959 & 0,0188 & 0,244 & 83,3 & 16,7 & 0,0 \\
\hline 166 & Pintadinho & 5 & 0,0242 & 16,0211 & 0,0775 & 1,1427 & 0,0055 & 0,099 & 40,0 & 60,0 & 0,0 \\
\hline 167 & Piqui & 32 & 0,1547 & 221,2883 & 1,0701 & 14,2790 & 0,0690 & 0,980 & 78,1 & 18,8 & 3,1 \\
\hline 168 & Piquiarana & 2 & 0,0097 & 19,3727 & 0,0937 & 1,2175 & 0,0059 & 0,077 & 100,0 & 0,0 & 0,0 \\
\hline 169 & Pitaíca & 6 & 0,0290 & 29,3631 & 0,1420 & 1,9658 & 0,0095 & 0,148 & 50,0 & 50,0 & 0,0 \\
\hline 170 & Pororoca & 29 & 0,1402 & 109,2119 & 0,5281 & 7,5837 & 0,0367 & 0,622 & 86,2 & 13,8 & 0,0 \\
\hline 171 & Quaruba & 2 & 0,0097 & 16,4718 & 0,0797 & 1,0474 & 0,0051 & 0,069 & 100,0 & 0,0 & 0,0 \\
\hline 172 & Quina-quina-amarela & 4 & 0,0193 & 14,3012 & 0,0692 & 1,0012 & 0,0048 & 0,084 & 25,0 & 25,0 & 50,0 \\
\hline 173 & Roxinho & 49 & 0,2369 & 206,7769 & 0,9999 & 14,1181 & 0,0683 & 1,115 & 85,7 & 10,2 & 4,1 \\
\hline 174 & Samaúma & 62 & 0,2998 & 600,3062 & 2,9028 & 37,7290 & 0,1824 & 2,401 & 91,9 & 8,1 & 0,0 \\
\hline 175 & Samaúma-barriguda & 5 & 0,0242 & 58,0118 & 0,2805 & 3,6058 & 0,0174 & 0,222 & 80,0 & 20,0 & 0,0 \\
\hline 176 & Samaúma-preta & 19 & 0,0919 & 143,1080 & 0,6920 & 9,1656 & 0,0443 & 0,616 & 89,5 & 10,5 & 0,0 \\
\hline
\end{tabular}


ACTA

AMAZONICA

Anexo 3 - Continuação.

\begin{tabular}{|c|c|c|c|c|c|c|c|c|c|c|c|}
\hline \multirow{2}{*}{$\mathbf{N}$} & \multirow{2}{*}{ ESPÉCIE } & \multirow{2}{*}{ NT } & \multirow{2}{*}{$\begin{array}{c}\mathbf{A B} \\
\left(\mathrm{N}^{-h^{-1}}\right)\end{array}$} & \multirow{2}{*}{$\begin{array}{l}\text { VT } \\
\left(\mathrm{m}^{3}\right)\end{array}$} & \multirow{2}{*}{$\begin{array}{c}\mathbf{V} \\
\left(\mathrm{m}^{3} \cdot \mathrm{ha}^{-1}\right)\end{array}$} & \multirow{2}{*}{$\begin{array}{l}\text { ABsT } \\
\left(\mathrm{m}^{2}\right)\end{array}$} & \multirow{2}{*}{$\begin{array}{c}\text { ABs } \\
\left(\mathrm{m}^{2} \cdot \mathrm{ha}^{-1}\right)\end{array}$} & \multirow{2}{*}{$\begin{array}{l}\text { IND } \\
(\%)\end{array}$} & \multicolumn{3}{|c|}{ COND. TORA (\%) } \\
\hline & & & & & & & & & 1 & 2 & 3 \\
\hline 177 & Sapota & 1 & 0,0048 & 4,7344 & 0,0229 & 0,3183 & 0,0015 & 0,024 & 100,0 & 0,0 & 0,0 \\
\hline 178 & Seringarana & 4 & 0,0193 & 18,9629 & 0,0917 & 1,2746 & 0,0062 & 0,097 & 100,0 & 0,0 & 0,0 \\
\hline 179 & Seringueira & 161 & 0,7785 & 879,0215 & 4,2506 & 58,0973 & 0,2809 & 4,248 & 80,7 & 18,0 & 1,2 \\
\hline 180 & Sorva & 1 & 0,0048 & 2,6945 & 0,0130 & 0,1987 & 0,0010 & 0,018 & 100,0 & 0,0 & 0,0 \\
\hline 181 & Sucupira-amarela & 14 & 0,0677 & 65,5570 & 0,3170 & 4,4139 & 0,0213 & 0,338 & 92,9 & 7,1 & 0,0 \\
\hline 182 & Sucupira-branca & 1 & 0,0048 & 3,7523 & 0,0181 & 0,2607 & 0,0013 & 0,021 & 100,0 & 0,0 & 0,0 \\
\hline 183 & Sucupira-preta & 1 & 0,0048 & 2,3602 & 0,0114 & 0,1790 & 0,0009 & 0,017 & 100,0 & 0,0 & 0,0 \\
\hline 184 & Taboarana & 26 & 0,1257 & 90,0591 & 0,4355 & 6,3382 & 0,0306 & 0,534 & 50,0 & 30,8 & 19,2 \\
\hline 185 & Tamarina & 34 & 0,1644 & 155,6269 & 0,7525 & 10,5088 & 0,0508 & 0,809 & 76,5 & 17,6 & 5,9 \\
\hline 186 & Taperebá & 1 & 0,0048 & 4,0013 & 0,0193 & 0,2753 & 0,0013 & 0,022 & 100,0 & 0,0 & 0,0 \\
\hline 187 & Tatajuba & 1 & 0,0048 & 3,9009 & 0,0189 & 0,2694 & 0,0013 & 0,022 & 0,0 & 100,0 & 0,0 \\
\hline 188 & Tauari & 171 & 0,8269 & 1287,3451 & 6,2251 & 82,4539 & 0,3987 & 5,545 & 90,1 & 8,8 & 1,2 \\
\hline 189 & Taxi-branco & 5 & 0,0242 & 14,0238 & 0,0678 & 1,0255 & 0,0050 & 0,093 & 60,0 & 0,0 & 40,0 \\
\hline 190 & Taxi-preto & 56 & 0,2708 & 223,6756 & 1,0816 & 15,3936 & 0,0744 & 1,238 & 87,5 & 12,5 & 0,0 \\
\hline 191 & Taxi-vermelho & 13 & 0,0629 & 57,5891 & 0,2785 & 3,9057 & 0,0189 & 0,304 & 100,0 & 0,0 & 0,0 \\
\hline 192 & Taxirana & 6 & 0,0290 & 26,3695 & 0,1275 & 1,7905 & 0,0087 & 0,140 & 83,3 & 16,7 & 0,0 \\
\hline 193 & Timbaúba & 8 & 0,0387 & 71,0657 & 0,3436 & 4,4934 & 0,0217 & 0,291 & 87,5 & 12,5 & 0,0 \\
\hline 194 & Torém & 10 & 0,0484 & 41,5180 & 0,2008 & 2,8413 & 0,0137 & 0,226 & 80,0 & 10,0 & 10,0 \\
\hline 195 & Torém-de-lixa & 1 & 0,0048 & 2,3602 & 0,0114 & 0,1790 & 0,0009 & 0,017 & 100,0 & 0,0 & 0,0 \\
\hline 196 & Torém-imbaúba & 1 & 0,0048 & 2,3602 & 0,0114 & 0,1790 & 0,0009 & 0,017 & 100,0 & 0,0 & 0,0 \\
\hline 197 & Ucuuba-branca & 24 & 0,1161 & 85,3513 & 0,4127 & 5,9807 & 0,0289 & 0,500 & 83,3 & 8,3 & 8,3 \\
\hline 198 & Ucuuba-preta & 3 & 0,0145 & 15,7214 & 0,0760 & 1,0440 & 0,0050 & 0,077 & 100,0 & 0,0 & 0,0 \\
\hline 199 & Ucuuba-punã & 1 & 0,0048 & 2,3602 & 0,0114 & 0,1790 & 0,0009 & 0,017 & 0,0 & 100,0 & 0,0 \\
\hline 200 & Vela-branca & 3 & 0,0145 & 10,2688 & 0,0497 & 0,7241 & 0,0035 & 0,061 & 100,0 & 0,0 & 0,0 \\
\hline 201 & Violeta & 50 & 0,2418 & 200,1193 & 0,9677 & 13,7681 & 0,0666 & 1,106 & 86,0 & 10,0 & 4,0 \\
\hline 202 & Xixá & 64 & 0,3095 & 283,2447 & 1,3697 & 19,2130 & 0,0929 & 1,495 & 78,1 & 21,9 & 0,0 \\
\hline 203 & Xixá-casca-dura & 7 & 0,0338 & 28,5608 & 0,1381 & 1,9595 & 0,0095 & 0,156 & 85,7 & 14,3 & 0,0 \\
\hline 204 & Xixuá & 1 & 0,0048 & 2,6093 & 0,0126 & 0,1937 & 0,0009 & 0,018 & 100,0 & 0,0 & 0,0 \\
\hline \multirow[t]{2}{*}{205} & Desconhecida & 98 & 0,4739 & 450,7844 & 2,1798 & 30,4205 & 0,1471 & 2,339 & 81,6 & 17,3 & 1,0 \\
\hline & TOTAL & 3518 & 17,0097 & 21667,4122 & 104,7735 & 1413,7669 & 6,8368 & 100,000 & 83,2 & 14,0 & 2,8 \\
\hline
\end{tabular}

Onde:

$\mathrm{N}=$ número seqüencial

ESPECIE = nome usual da espécie

$\mathrm{NT}=$ número total de árvores

$\mathrm{AB}=$ abundância (árvores.ha-1)

$\mathrm{VT}=\operatorname{volume}$ total $\left(\mathrm{m}^{3}\right)$

$\mathrm{V}=$ volume por hectare $\left(\mathrm{m}^{3} \cdot \mathrm{ha}^{-1}\right)$

$\mathrm{V}=$ volume por hectare $\left(\mathrm{m}^{3}\right.$
$\mathrm{ABST}=$ área basal total $\left(\mathrm{m}^{2}\right)$

ABs = área basal por hectare $\left(\mathrm{m}^{2} . \mathrm{ha}^{-1}\right)$

IND $(\%)=$ índice de importância da espécie (percentual)

COND. TORA $(\%)=$ condição de aproveitamento da tora (percentual)

1 - tora com aproveitamento total

2 - tora com aproveitamento parcial

3 - tora sem aproveitamento

Desconhecida = dados referentes ao conjunto das árvores não identificadas no inventário a $100 \%$ 
